\title{
A model-based performance test for forest classifiers on remote-sensing imagery
}

\author{
Stéphane Couturier ${ }^{\mathrm{a}, \mathrm{b}, *}$, Jean-Philippe Gastellu-Etchegorry ${ }^{\mathrm{a}, 1}$, Pavka Patiño ${ }^{\mathrm{c}, 2}$, Emmanuel Martin ${ }^{\mathrm{a}, \mathrm{d}, 3}$ \\ a Centre d'Etudes Spatiale de la Biosphère (CESBIO), CNES/CNRS/Paul Sabatier University, 18 Avenue Edouard Belin, 31401 Toulouse Cedex 4, France \\ ${ }^{\mathrm{b}}$ Laboratorio de Análisis Geo-Espacial (LAGE), Instituto de Geografía, Universidad Nacional Autónoma de México (UNAM), Circuito Exterior, Cd Universitaria, \\ Apdo Postal 20850, CP: 04510 México, DF, Mexico \\ ' Centro de Investigaciones en Ecosistemas (CIECO), Universidad Nacional Autónoma de México (UNAM), Antigua Carretera a Pátzcuaro 8701, \\ Col. Ex Hacienda de San José de la Huerta, C.P. 58190, Morelia, Michoacán, Mexico \\ ${ }^{\mathrm{d}}$ MAGELLIUM, 24 rue Hermes 31520 Ramonville Saint Agne, Toulouse, France
}

\section{A R T I C L E I N F O}

Article history:

Received 24 January 2008

Received in revised form 8 August 2008

Accepted 11 August 2008

Keywords:

3D model

DART

Contextual classification

Density function

IKONOS

Very high resolution image

Mexico

\begin{abstract}
A B S T R A C T
Ambiguity between forest types on remote-sensing imagery is a major cause of errors found in accuracy assessments of forest inventory maps. This paper presents a methodology, based on forest plot inventory, ground measurements and simulated imagery, for systematically quantifying these ambiguities in the sense of the minimum distance (MD), maximum likelihood (ML), and frequency-based (FB) classifiers. The method is tested with multi-spectral IKONOS images acquired on areas containing six major communities (oak, pine, fir, primary and secondary high tropical forests, and avocado plantation) of the National Forest Inventory (NFI) map in Mexico. A structural record of the canopy and optical measurements (leaf area index and soil reflectance) were performed on one plot of each class. Intra-class signal variation was modelled using the Discrete Anisotropic Radiative Transfer (DART) simulator of remote-sensing images. Atmospheric conditions were inferred from ground measurements on reference surfaces and leaf optical properties of each forest type were derived from the IKONOS forest signal. Next, all forest types were simulated, using a common environmental configuration, in order to quantify similarity among all forest types, according to MD, ML and FB classifiers. Classes were considered ambiguous when their dissimilarity was smaller than intra-class signal variation.

DART proved useful in approximating the pixel value distribution and the ambiguity pattern measured on real forest imagery. In the case study, the oak forest and the secondary tropical forest were both distinguishable from all other classes using an MD classifier in a $25 \mathrm{~m}$ window size, whereas pine and primary tropical forests were ambiguous with three other classes using MD. By contrast, only two pairs of classes were found ambiguous for the ML classifier and only one for the FB classifier in that same window size. The avocado plantation was confounded with the primary tropical forest for all classifiers, presumably because the reflectance of both types of forest is governed by a deep canopy and a similar shadow area. We confronted the results of this study with the confusion matrix from the accuracy assessment of the NFI map. An asset of this model-based method is its applicability to a variety of sensor types, eco-zones and class definitions.
\end{abstract}

(c) 2008 Elsevier B.V. All rights reserved.

\footnotetext{
* Corresponding author at: Laboratorio de Análisis Geo-Espacial (LAGE), Instituto de Geografía, Universidad Nacional Autónoma de México (UNAM), Circuito Exterior, Cd Universitaria, Apdo Postal 20850, CP: 04510 México, DF, Mexico.

Tel.: +52 55562302 22x45 488; fax: +52 5556162145 .

E-mail addresses: andres@igg.unam.mx, stephcamelo@mailcity.com (S. Couturier), gastellu@cesbio.cnes.fr (J.-P. Gastellu-Etchegorry), pav_k@oikos.unam.mx (P. Patiño), emmanuel.martin@magellium.fr (E. Martin).

1 Tel.: +33561556130.

2 Tel: $+524433222777 \times 42536$

3 Tel.: +33 562247019 .
}

\section{Introduction}

The classification of remote-sensing images for forest cartography is essential to regional biodiversity mapping. Yet, because of the heterogeneity of forest settings, the distinction between forest types remains a difficult challenge. The application of common automatic classifiers (e.g. ISODATA, $K$-means) and visual labelling of the resulting unsupervised clusters still seem, at least until recently, a widely used strategy in operational forest mapping programs at regional scale (i.e., Benjamin et al., 1996; Vogelmann et al., 2001; Wulder et al., 2003). Comprehensive or partial accuracy assessments of these maps were achieved (Laba et al., 2002; Wickham et al., 2004; Remmel et al., 2005). At high

0378-1127/\$ - see front matter (c) 2008 Elsevier B.V. All rights reserved. doi:10.1016/j.foreco.2008.08.017 
taxonomic resolution, confidence levels reported for many forest classes were lower than those reported in other studies on the same type of imagery with more sophisticated classifiers (e.g. Magnussen et al., 2004; Salovaara et al., 2005; Lu et al., 2003). However, the latter studies occurred in more confined, more homogeneous geographical areas and concerned a smaller number of classes. In some of these case studies, classifiers with ancillary information on forest stand structure yield better accuracy than the one obtained with classifiers that do not incorporate such information. For example, Spectral Mixture Analysis (SMA) uses spectral end-members (shadow or sunlit fractions) that contain sub-pixel structural information, and SMA yielded accuracy improvements for the classification of successional stages of the Amazonian tropical forest (Lu et al., 2003). Moreover, Lu (2005) found that a more detailed structural information (the measurement of tree height distribution on the ground) was highly correlated with a combination of Landsat TM bands; a linear regression of these quantities further improved the accuracy of the classification. A drawback of these approaches, however, is again their limited transferability to broader scales, other forest communities, or other remote-sensing configurations. Indeed, the relationships that linked forest stand structural information to the reflectance data were empirically derived and only valid for the environment close to the image at hand ( $\mathrm{Lu}, 2005)$. From these observations, a set of questions may be posed by the forest map producer in a highly biodiverse region: Would any more sophisticated classifier perform better than the common automatic classifiers at regional or national scales, for a wider set of forest classes? Or: For which set of forest classes is it worthwhile to look for better, more sophisticated, algorithms instead of settling for the commonly used (or available) classifiers?

Considering the above-mentioned improvements in accuracy, one way to address these questions could be to refer to an expert system, based on the description of the structure of forest stands, capable of estimating a priori ambiguities among classes for a given classifier. Indeed, high ambiguity between two forest types for a few conventional classifiers would encourage the forest map producer to look for a more sophisticated classifier. Such result could even pose the question of whether it is suitable to classify these forest types via automatic classification or if it is preferable to use visual classification instead, a strategy employed for example in the case of the National Forest Inventory (NFI) in Mexico (Mas et al., 2002; Mas and Ramírez, 1996). Conversely, low ambiguity between two forest types for a given classification method would ensure the appropriateness of the classification method and stop the quest for a better classifier (e.g. Baban and Kamaruzaman, 2001, in a sub-tropical setting). It is recently argued indeed (Wilkinson, 2005) that more research efforts should be dedicated to improving other areas of the map production process (Fassnacht et al., 2006) rather than mainly focusing on better classification algorithms.

In this research, we propose a framework based on forest plot inventory, ground measurements and simulated imagery, in order to test a few classifiers' a priori performance on pairs of classes among a given set of forest types and for any given remote-sensing platform. This framework is applied to the case of 6 forest types pertaining to classes at community level (Palacio-Prieto et al., 2000) of the Mexican NFI map (see Mas et al., 2002), namely oak, pine, fir, primary and secondary high tropical forests, and avocado plantation.

\section{Background}

3D modeling of forest plots offers various advantages to foresters. For example, it allows tree mapping based on plot inventory, which enables the precise estimation of key structural indices of the forest such as canopy gap distribution (Silbernagel and Moeur, 2001). Additionally, radiative transfer coupled with 3D modeling has permitted the evaluation of radiation budgets of forest parcels and intercepted radiation by tree crowns (e.g. Gastellu-Etchegorry and Trichon, 1998; Courbaud et al., 2003). In terms of bi-directional reflectance, the comparison between simulated and real imagery of forests is a difficult task. At scales well above tree crown, the average signal is dominated by the macroscopic properties of illuminated and shadowed crown and ground components. In this case, the average reflectance of homogeneous stands is simulated with forward models of canopy scattering (e.g. Goel and Thompson, 2000; North, 1996; Pinty and Verstraete, 1991; Strahler, 1996). This approach has been successfully assessed against real imagery in mainly coniferous stands made of repeated individuals of one or two species (Gemmel and Varjo, 1999; Courbaud et al., 2003; Disney et al., 2006). No such exercise was achieved for scales approaching crown size and with a flexible scheme integrating a greater diversity of tree species and heterogeneous understory spectral signatures.

The 3D Discrete Anisotropic Radiative Transfer (DART ${ }^{4}$ ) raytracing model (Gastellu-Etchegorry et al., 2004) simulates remotesensing images of heterogeneous natural and urban landscapes, using 3D generic representations of these landscapes. This simulator has been successfully tested against reflectance results of other radiative transfer models (Pinty et al., 2004). GastelluEtchegorry and Trichon (1998) stress the difficulty in accurately positioning a simulated plot on a $25 \mathrm{~m}$ resolution imagery. Simulating remote-sensing imagery and not only average reflectance allows to work at resolutions close to crown scales. At very high (1-5 $\mathrm{m}$ ) resolution, more recently available, forest plots are more easily identifiable on the image, and the amount of ground measurements necessary for statistically meaningful comparisons between simulated and real pixel sets is at least $5^{2}=25$ times less extensive than for $25 \mathrm{~m}$ resolution imagery, in which a one hectare plot contains only 16 pixels. Multi-spectral IKONOS imagery $(4 \mathrm{~m}$ resolution) has recently been used for the classification of taxonomically close forests (e.g. Wang et al., 2004; Thenkabail et al., 2004).

We used the DART model to simulate the inherent heterogeneity of forest stands and the associated IKONOS multi-spectral remote-sensing images. This paper describes an approach that is essentially generic, and examines the utility of a 3D structural model with general assumptions on the canopy, in order to test the correspondence of such general model with the structural information given by $4 \mathrm{~m}$ multi-spectral imagery of a large variety of forest types. Our goal was to study ambiguities among these forest types on remote-sensing imagery in a systematic manner. For this purpose, a set of parameters, measurable in the field and in the laboratory, was handled as variables, while environmental heterogeneity exterior to the forest setting (viewing and illumination configurations, sensor response and atmospheric scattering) was controlled and fixed.

Clusters from commonly available unsupervised classifiers such as ISODATA or $K$-means are organized around the minimum distance (MD) principle. Another conventional parametric method is the maximum likelihood (ML) classifier. MD and ML principles were selected for the ambiguity estimate concerning relatively common classifiers. Among more sophisticated methods, the frequency-based (FB) classifiers have been successfully used for contextual image classification of very high resolution imagery (Lira and Maletti, 2002; Xu et al., 2003). The first order FB classifier

\footnotetext{
${ }^{4}$ DART is a patented model that is freely available for scientific applications at www.cesbio.cnes.fr.
} 
is built on the quantitative comparison of histograms - or density functions - of pixel neighbourhoods (Maletti et al., 2002). A classifier was considered to perform well at distinguishing a pair of classes if the spectral dissimilarity between images of simulated plots of these classes (or 'inter-class variation') was higher than the spectral dissimilarity among simulated plots within a given class (or 'intra-class variation'). In the opposite case, i.e., if inter-class variation was lower than intra-class variation, the classes were considered ambiguous for this classifier. The spectral distance characterizing each classifier is defined in the section on classifiers' dissimilarity measures. For example, the Euclidian distance between mean spectral values defines spectral dissimilarity for the MD criterion.

In this work, a botanic inventory, including a structural record of the canopy, was performed on 6 forest plots (one per forest type) appearing on 3 IKONOS scenes (multi-spectral and panchromatic). Optically based measurements were conducted in order to estimate the Leaf Area Index (LAI) and the reflectance of the understory in each plot. These measurements and environmental parameters matching conditions of the IKONOS overpasses served as inputs to the DART model for the simulation of the forest plots. The comparison of each simulated image against its corresponding IKONOS scene allowed us to account for atmospheric effects and to compute the leaf optical properties of each forest type through an imagery calibration process, as indicated in the section on satellite imagery. In order to test the potential of DART for simulating the 4 m-resolution real IKONOS imagery of the forest plots, the histograms of simulated and real imagery were compared.

In a second step, for ambiguity assessments, all forest plots were simulated under the acquisition and environmental conditions of one IKONOS scene. The variability of measurements within a given forest type was assessed on the ground and images of plots of the same forest type were generated from simulations incorporating this variability. Inter-class and intra-class variations were derived and pair-wise comparisons were made for all combinations of the 6 forest types. The aim of this exercise was to enlist, for each of the three classifying methods and for a specific window size, pairs of classes that are a priori ambiguous and pairs of classes that are a priori separable. Finally, in the last part of the paper, we discuss the results of this study in the context of the confusions recorded among the same classes, in a previous accuracy assessment of the NFI map.

\section{Study areas}

An extensive coverage of both temperate and tropical types of forests is reported by the NFI map of mega-diverse Mexico (Mas et al., 2002). Much spatial intricacy occurs among polygons of forest classes at community level, even between patches of temperate and tropical forests (see for example the NFI map of the state of Chiapas), the distinction of which is an important task for biodiversity mapping. We focused on three sites that contain a variety of forest types included in the classification system of the NFI and where IKONOS imagery was available. Two sites, labelled 'Tancítaro' and 'Cuitzeo', are located on the transversal volcanic chain and contiguous altiplano in central western Mexico (see Figs. 1 and 2). The 'Tancítaro' site is included in the communal lands of San Juan Parangaricutiro, Michoacán state, near to the natural reserve of the Tancitaro volcano peak. This site is about $2200 \mathrm{~m}$ above sea level and the climate is close to temperate subhumid. The 'Cuitzeo' site is located in the ejidal lands of El Cerro, Michoacán state, close to the Cuitzeo lake. This site is about $2050 \mathrm{~m}$ above sea level and the climate is intermediate between tropical dry and temperate sub-humid. Another site, labelled 'Los Tuxtlas', is situated near to the coast of the Gulf of Mexico (see Fig. 2), on the flanks of the San Martin volcano at about $900 \mathrm{~m}$ above sea level. This site is included in the communal lands of La Perla de San Martin, Veracruz state, within the biosphere reserve of Los Tuxtlas. The climate is mainly characterized by tropical humid conditions.

We focused on six forest plots (listed in Table 1) among these three sites. One plot pertains to an oak forest dominated by Quercus deserticola in the Cuitzeo site; one plot of pine forest dominated by Pinus montezumae, one plot of fir forest dominated by Abies religiosa and one plot of avocado plantation (Persea americana)

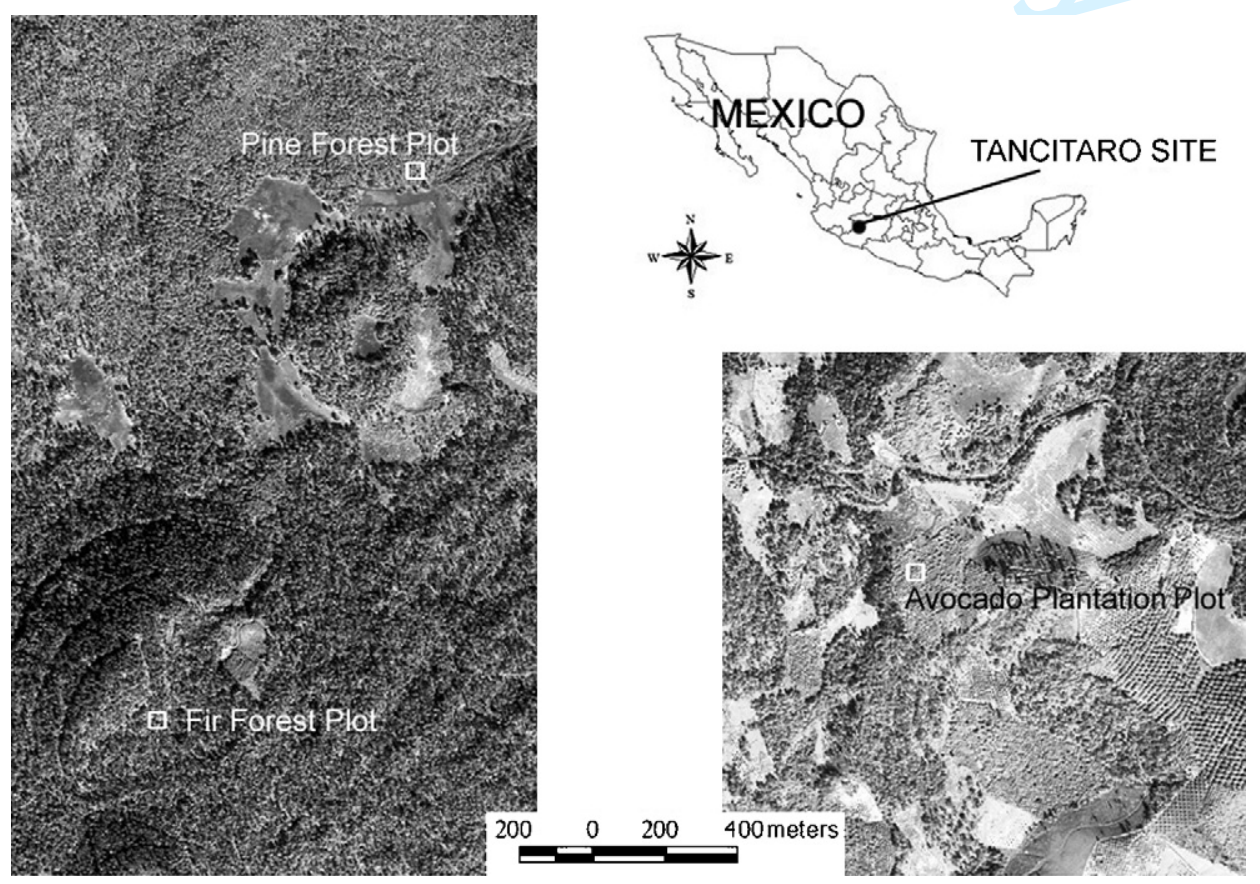

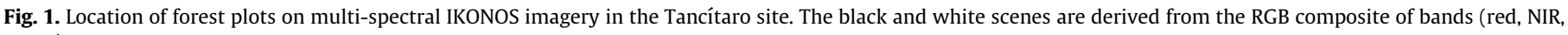
green). 

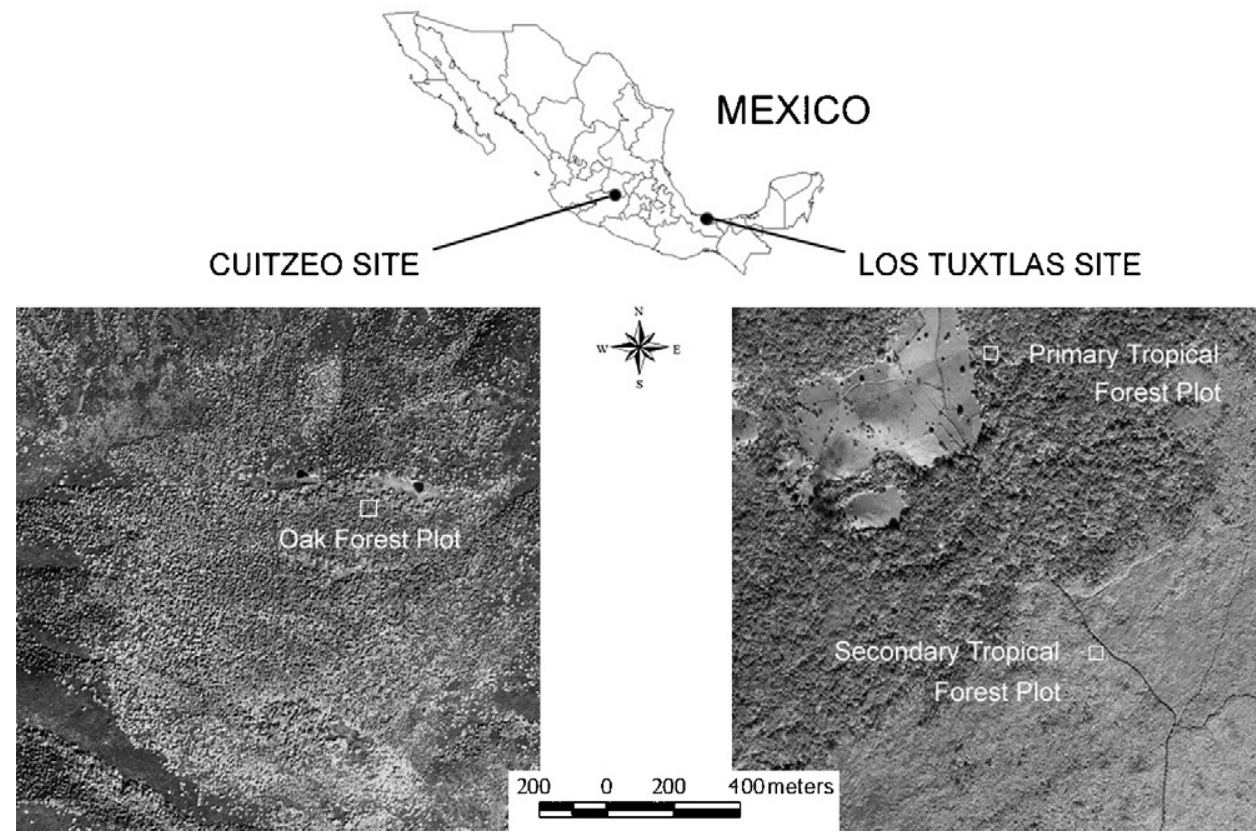

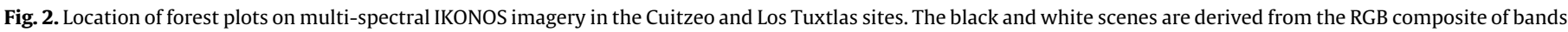
(red, NIR, green).

Table 1

Structural parameters of forest plots and stands

\begin{tabular}{|c|c|c|c|c|c|c|c|c|}
\hline \multirow[t]{2}{*}{ Forest stand } & \multirow[t]{2}{*}{ Site } & \multirow{2}{*}{$\begin{array}{l}\text { Number } \\
\text { of species }\end{array}$} & \multirow{2}{*}{$\begin{array}{l}\text { Plot } \\
\text { size }(\mathrm{m})\end{array}$} & \multirow{2}{*}{$\begin{array}{l}\text { Crown } \\
\text { Cover in plot (\%) }\end{array}$} & \multirow{2}{*}{$\begin{array}{l}\text { Crown Cover in } \\
\text { forest stand (\%) }\end{array}$} & \multirow{2}{*}{$\begin{array}{l}\text { LAI in } \\
\text { plot }\end{array}$} & \multicolumn{2}{|c|}{ LAI in forest stand } \\
\hline & & & & & & & Min & $\operatorname{Max}$ \\
\hline Oak & Cuitzeo & 12 & $50 \times 50$ & 64 & $54-72$ & 2.5 & 2.0 & 3.2 \\
\hline Pine & Tancítaro & 3 & $50 \times 50$ & 87 & $75-94$ & 3.5 & 2.9 & 4.1 \\
\hline Fir & Tancítaro & 6 & $50 \times 50$ & 75 & $59-86$ & 3.9 & 2.6 & 5.8 \\
\hline Avocado & Tancítaro & 1 & $50 \times 50$ & 77 & $72-85$ & 6.1 & 5.6 & 6.4 \\
\hline Trop. Second. & Tuxtlas & 21 & $40 \times 40$ & 96 & $92-98$ & 5.1 & 4.5 & 6.1 \\
\hline Trop. high & Tuxtlas & 31 & $40 \times 40$ & 97 & $92-100$ & 7.9 & 7.0 & 8.9 \\
\hline
\end{tabular}

were selected in the managed forests of Tancitaro; one plot of mature, well-preserved high tropical forest ('primary' tropical forest) and one plot of secondary tropical forest were selected in the Los Tuxtlas site. The secondary forest was regenerating vegetation on a site where primary forest had been depleted by a 1998 fire episode. All plots are lying on relatively flat terrain. Thereafter, we denominate 'forest stand' as being a larger portion of forest of the same type, on relatively flat terrain, that includes the forest plot.

\section{Ground measurements}

For each forest class, we proceeded to the survey of one plot and five reference parcels within the same forest stand. The data collected in the reference parcels were used to model the intraclass variation of the signal. A structural record of the canopy (including the detailed position of individual crowns, see below) was measured in the forest plot. Crown coverage (CC) estimation, LAI measurements and soil reflectance evaluation (see Section 4.2) were performed in the plot as well as in the reference parcels.

\subsection{Forest stand structure}

The square-shaped forest plots (see dimensions on Table 1) were marked with metric tapes to register the relative position of trees. All trees larger than $10 \mathrm{~cm}$ diameter at breast height $(\mathrm{DBH})$ were inventoried in the plot of primary tropical forest, and larger than $5 \mathrm{~cm}$ DBH in all other plots. Species were identified (the number of species is mentioned in Table 1) and crown dimensions were measured assuming an ellipsoidal envelope, the axes of which are aligned to the orientation of the parcel: the extreme horizontal coordinates of the ellipsoidal envelope were visually evaluated on the metric tape using compasses. Vertical dimensions were assessed by the local foresters guiding the team in the field, using reference trees whose height was estimated with a clinometer. In some cases, more than one ellipsoid was required to approximate the crown. Trees with stems outside the plot but whose crown infringed in the plot were also measured and included in the simulation. With the aid of two metric tapes placed perpendicularly across the entire plot (or reference parcel), CC was measured (see Table 1) as the fraction of the tapes that intersected the projected crowns on the ground.

These measurements were synthesized into an ASCII file, which was converted by the DART model into a 3D representation based on turbid or empty cubic cells for the canopy, and opaque surfaces for tree trunks (Fig. 3; see Gastellu-Etchegorry et al., 2004). The volume of the ellipsoids was 'filled' with turbid cells (simulating leaves) or air cells (simulating holes in the canopy) according to a probability of presence or filling index (see Gastellu-Etchegorry, 2006). In a preliminary step, a set of filling indices was tested for the simulation of large trees in each forest setting. The filling index which visually approximated the texture appearance of these large 


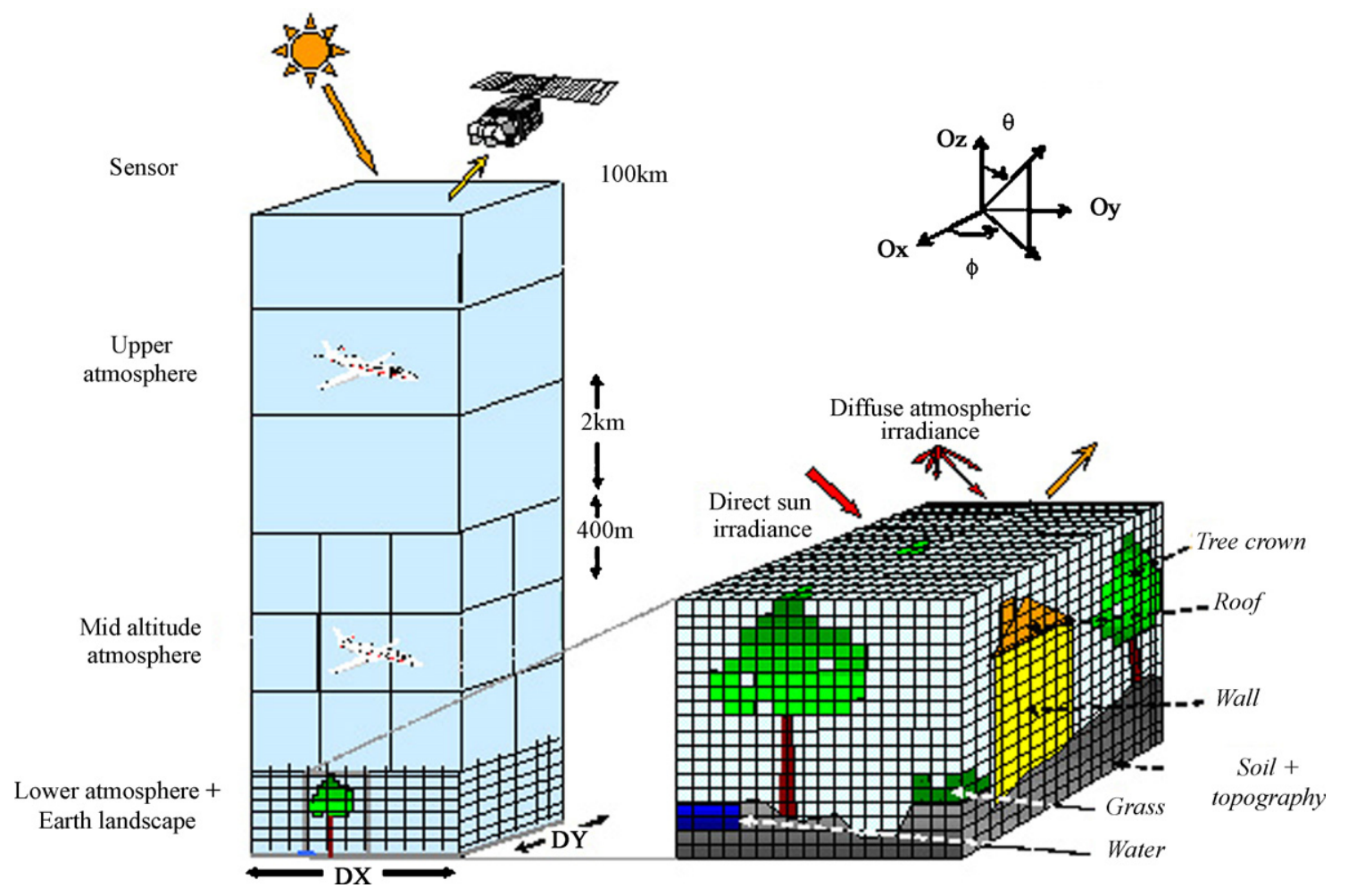

Fig. 3. DART representation of the landscape- atmosphere-sensor system. Taken from Martin (2006).

trees on the real $1 \mathrm{~m}$ panchromatic IKONOS was retained. The 3D structure and vertical profile of the canopy are illustrated with the JAVA 3D interface of the DART model in Figs. 4-9(a and b). The satellite imagery was simulated by the DART model, using 3D representations that comprised all measured trees (i.e., an area larger than the plot itself). However, data processing was conducted on the sub-images corresponding to the forest plots. This procedure was adopted to avoid any artificial shadow created by the absence of tree crowns at the border of the plots.

\subsection{Optical measurements}

We conducted a series of 16 LAI estimates in the plot and 10 LAI estimates in each reference parcel, using the SUNSCAN Canopy Analysis System (Delta-T Devices Ltd, Cambridge, UK). A linear probe containing 64 photodiodes measures the radiation intercepted by the canopy while at the same time, sensors with and without shade placed in a clearing read diffuse and direct sun radiations. The effective LAI is automatically derived according to the principles and assumptions detailed in Potter et al. (1996). The measurements with the apparatus were made along two $20 \mathrm{~m}$ long perpendicular transects within the plot and reference parcels. They were subsequently averaged. These average values are displayed in columns 7 and 8 of Table 1, respectively.

The measurement campaign occurred in March-April 2005, the season corresponding to the satellite overpass on Cuitzeo, the only site where forest LAI is strongly seasonally dependent. Since hemispherical photography (a technique which suffers less dependence on sun zenith angle for gap fraction estimation: Jonckheere et al., 2004, p. 31) was unavailable for our campaign, the emphasis of the study, rather than aim precise absolute LAI values, was to measure coherent LAI values among plots and sites. Therefore, we always realized measurements at a time of the day when the sun was at $35-40^{\circ}$ zenith angle, markedly away from noon but within the domain of LAI retrieval by the SUNSCAN software. The LAI estimates in forest plots and in reference parcels (extreme values) are shown in columns 7 and 8 of Table 1 , respectively.

Bare soil, rock and soil covered with different types of litter represented the ground conditions of all forest plots. In the presence of forest plots with sparse canopy or low LAI, an optical (a)

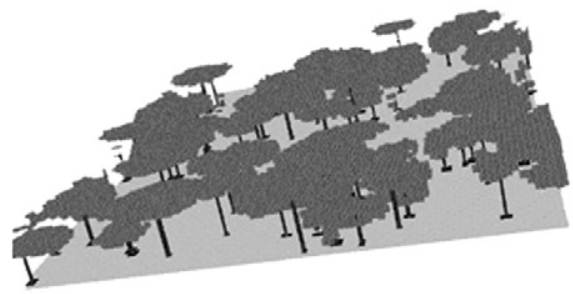

(b)

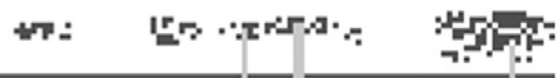

(c)

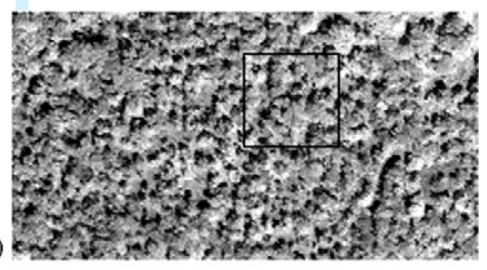

(d)

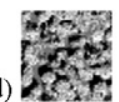

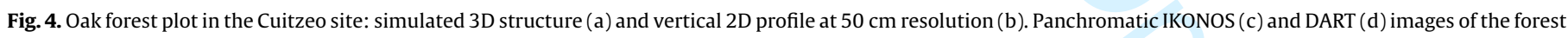
plot. The DART panchromatic image is derived from a fusion of DART multi-spectral images. 
(a)

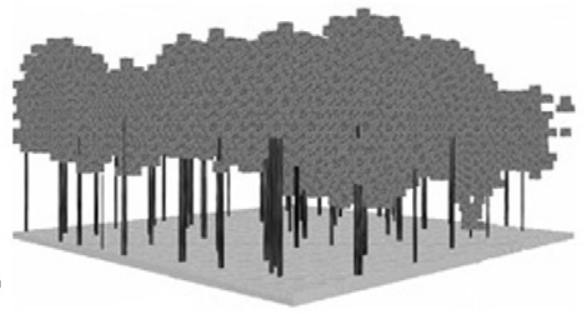

(b)

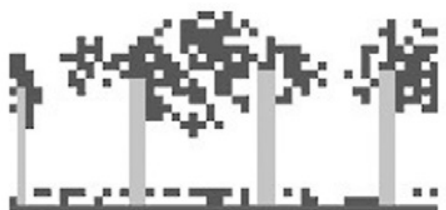

(c)

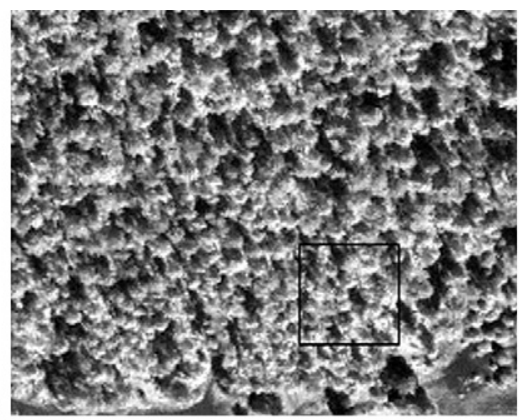

(d)

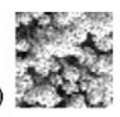

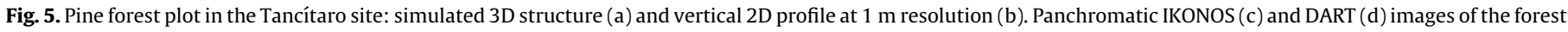
plot. The DART panchromatic image is derived from a fusion of DART multi-spectral images.

characterization of the understory was necessary (Pinty et al., 1998). The direct appraisal of the optical properties in the field was hindered by the heterogeneous ground conditions. Therefore, we first proceeded to a visual description of the understory in terms of quantitative fractions of biophysical constituents present on the ground over the whole forest plot. The biophysical constituents encountered in the field were then spectrally related to a reduced set of seven most frequent, conspicuous constituents: a type of humus-rich bare soil, a type of basaltic rock, litter of yellow dried grass, orange-brown leaf litter, dark brown leaf litter, grey (decomposed) leaf and branch litter, and brownish needle litter. These seven constituents were collected in the field and then arranged in the laboratory as opaque surfaces to reproduce spatially homogeneous understory scenarios.

Optical properties (i.e., directional reflectance) of homogeneous understory scenarios were measured in laboratory with illumination zenith angle similar to the ones of the IKONOS overpasses. For this purpose, a series of bi-directional measurements of the ground's upwelling radiance was taken using a 512-channel hand- held spectro-radiometer (Geophysical and Environmental Research Group [GER] 1500) operating at $3 \mathrm{~nm}$ FWHM over the range of wavelengths from $300 \mathrm{~nm}$ to $1050 \mathrm{~nm}$. The instrument was held $1 \mathrm{~m}$ above the targeted area. Mean reflectance spectra of homogeneous understories were computed after a normalization to the radiance response of a Labsphere Teflon reference panel, which diffusely reflects incident radiation over all angles.

In a second step, the reflectance of each 'real' understory was computed as a linear combination of the homogeneous understory spectra, with weights being the fractions observed in the field. This computation relies on a linear simplifying hypothesis that was successfully tested with field measurements of understories made of conspicuous patches of two constituents. In order to estimate the variability of soil reflectance in the surrounding forest, we similarly characterized the understory of the 5 reference parcels. The directional reflectance values, convolved to each IKONOS multi-spectral band, were inserted in the Hapke module (GastelluEtchegorry, 2006) of the DART model in order to obtain the coefficients of the Hapke (1993) soil model that fits them. These (a)

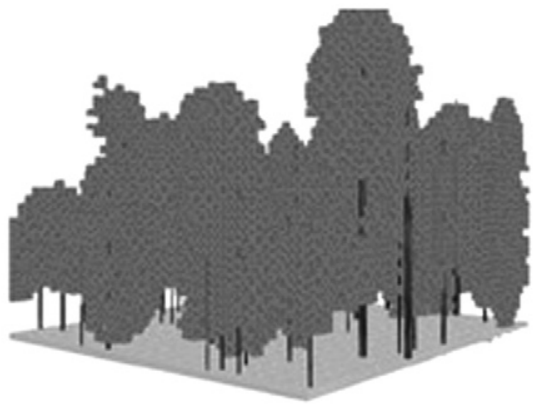

(b)

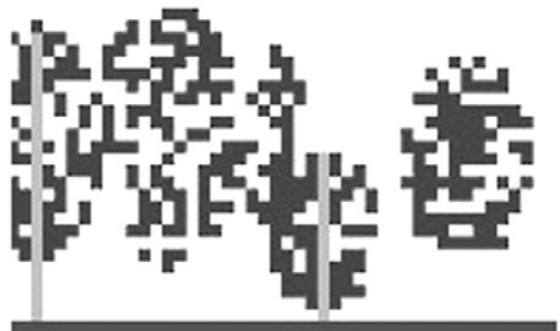

(c)

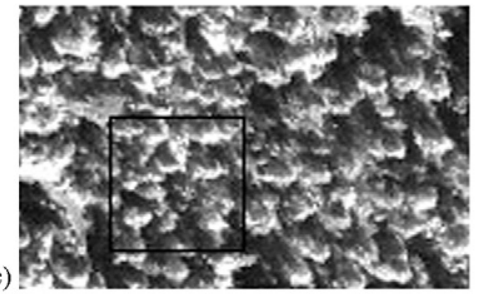

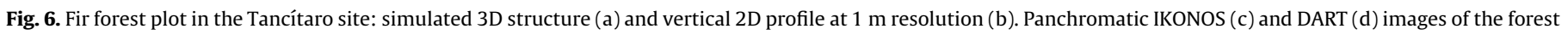
plot. The DART panchromatic image is derived from a fusion of DART multi-spectral images. 
(a)

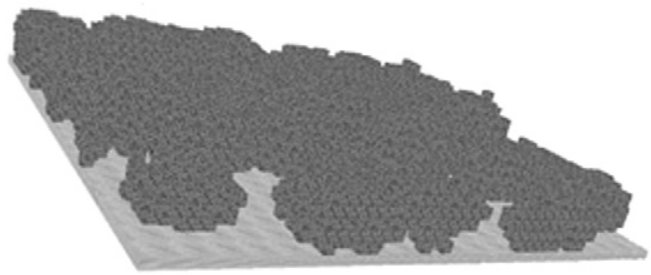

(c)

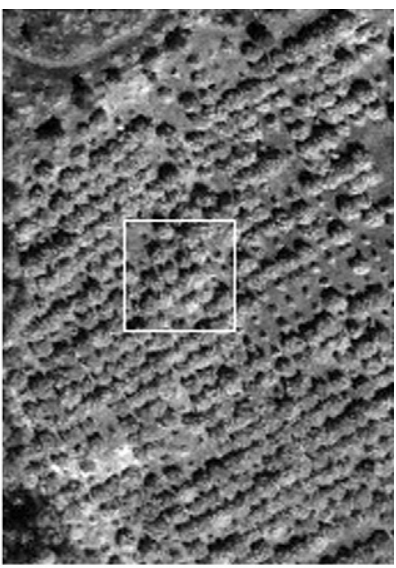

(b)

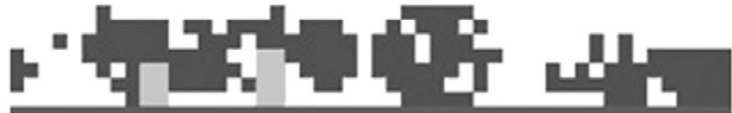

(d)

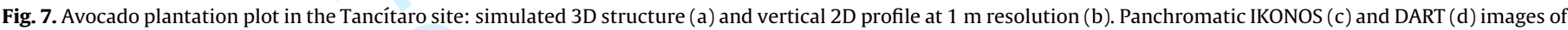
the plantation plot. The DART panchromatic image is derived from a fusion of DART multi-spectral images.

(a)
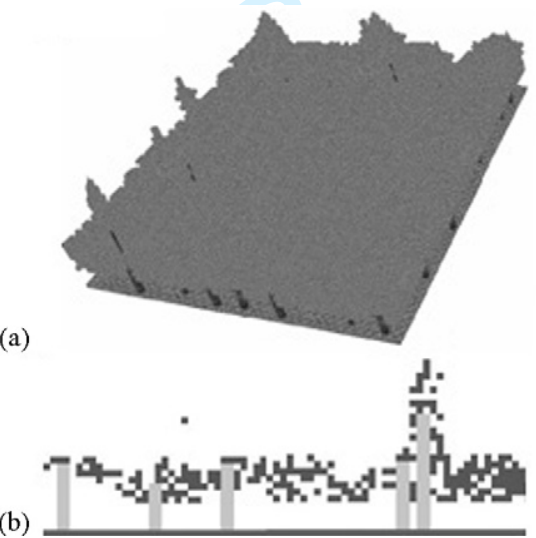

(c)

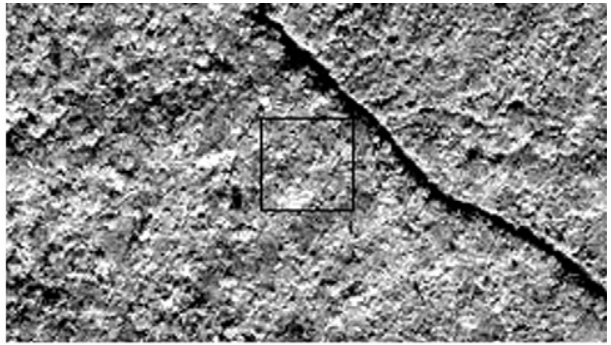

(d)

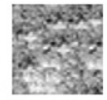

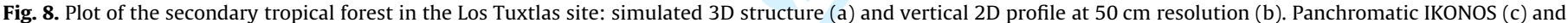
DART (d) images of the forest plot. The DART panchromatic image is derived from a fusion of DART multi-spectral images.

(a)
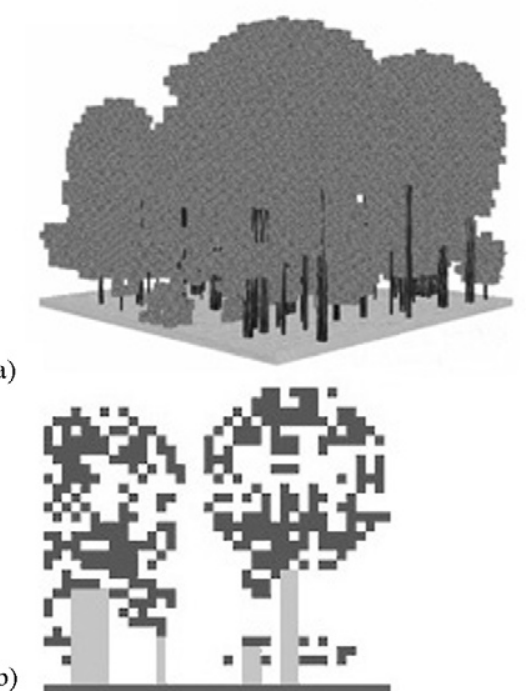

(c)

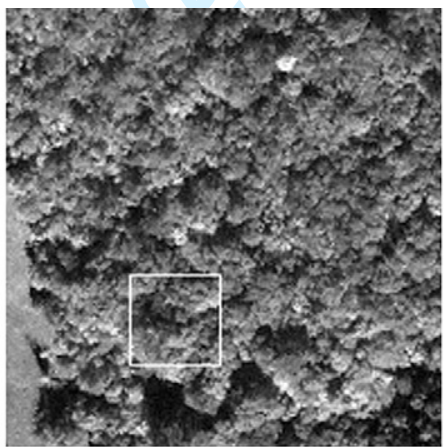

(d)

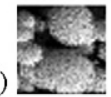

(e)

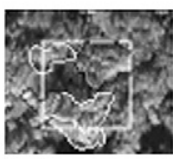

(f)

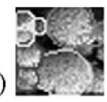

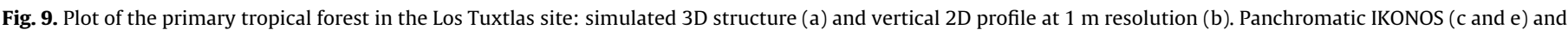

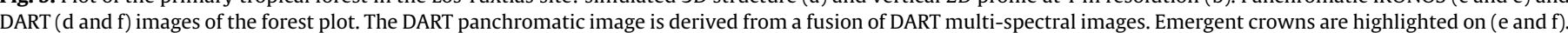


Table 2

Acquisition parameters of IKONOS imagery

\begin{tabular}{|c|c|c|c|c|c|c|c|c|}
\hline \multirow[t]{2}{*}{ Site } & \multicolumn{2}{|c|}{ Geometric coordinates } & \multirow[t]{2}{*}{ Date } & \multirow[t]{2}{*}{ Local time } & \multirow[t]{2}{*}{$\theta_{\mathrm{s}}\left({ }^{\circ}\right)$} & \multirow[t]{2}{*}{$\varphi_{\mathrm{s}}\left({ }^{\circ}\right)$} & \multirow[t]{2}{*}{$\theta_{\mathrm{v}}\left(^{\circ}\right)$} & \multirow[t]{2}{*}{$\varphi_{\mathrm{v}}\left(^{\circ}\right)$} \\
\hline & Latitude $\left({ }^{\circ}\right)$ & Longitude $\left({ }^{\circ}\right)$ & & & & & & \\
\hline Cuitzeo & 20.0 & -101.1 & $04 / 03 / 2003$ & $10: 36$ & 33.2 & 141.5 & 14.7 & 358.9 \\
\hline Tancítaro & 19.4 & -102.2 & $20 / 11 / 2002$ & $10: 47$ & 40.9 & 162.9 & 21.9 & 290.4 \\
\hline LosTuxtlas & 18.5 & -95.1 & $29 / 11 / 2004$ & $10: 04$ & 43.1 & 157.6 & 21.8 & 33.3 \\
\hline
\end{tabular}

$\theta_{\mathrm{s}}$ and $\varphi_{\mathrm{v}}$ refer to Sun zenith angle and viewer azimuth angle, respectively. Local time is GMT-7:00.

coefficients were used as descriptors of the understory optical properties in the simulation.

\section{Satellite imagery}

\subsection{Image preparation}

We acquired panchromatic and multi-spectral IKONOS scenes for each of the three sites (Figs. 1 and 2; Table 2). The scenes were provided in 'Standard Geometrically Corrected' mode by Space Imaging. They were subsequently geometrically corrected using GPS measurements.

In a first step, the panchromatic image was corrected via identifiable landmarks. We used a GARMIN ${ }^{\circledR}$ GPS unit (WAAS mode) to record tracks around crowns of isolated trees in clearings and along clearing borders/access trails in the vicinity of the forest plots. We then matched the IKONOS imagery to the GPS positions at less than $4 \mathrm{~m}$ RMS ( 1 pixel of the multi-spectral image), using a 2nd degree polynomial transformation. Forest plots were then located in the image through visual identification of pre-eminent trees or gaps in the panchromatic image. Alternatively, we used the average of repeated GPS readings inside the plot, using climbing equipment on trees when necessary, until getting less than $3 \mathrm{~m}$ location accuracy. Figs. 4-9(c) illustrate portions of the panchromatic IKONOS image where the forest plots are located. In a second step, the geometry of the multi-spectral images was corrected using the corresponding panchromatic image as a reference.

The multi-spectral IKONOS raw digital numbers were converted to top-of-atmosphere (TOA) reflectance using the standard solar irradiance formula provided by Space Imaging. No atmosphere measurement was available at IKONOS overpass. Besides, the limited equipment available for this study and the great diversity of leaves/needles present in the forest plots hindered the measurement of their optical properties. In the absence of available reflectance databases, we used measurements on homogeneous surfaces and in reference parcels of each IKONOS scene in order to infer atmospheric and leaf optical parameters from auxiliary simulations, as explained below.

\subsection{Image calibration}

Bi-directional measurements were acquired with the GER-1500 spectro-radiometer in at least two recognizable reference surfaces per IKONOS scene: large crossings of asphalted and dry dirt roads in Los Tuxtlas, gravel and asphalt roads in Tancítaro, crossing of asphalt roads and a small quarry site in Cuitzeo. The aerosol optical depth (AOD), and total transmittance of the vapour column $\left(T_{\mathrm{H}_{2} \mathrm{O}}\right)$, two major atmospheric parameters in the spectral bands of interest, were computed with the help of the simulated TOA reflectance of the two reference surfaces, assuming a tropical rural atmospheric model with $23 \mathrm{~km}$ visibility (Berk et al., 1989).

In order to calibrate the Leaf Optical Properties (LOP) of each forest plot, we considered IKONOS pixels associated with large LAI values in the reference parcels. These pixels were identified in the panchromatic IKONOS image as $8 \mathrm{~m} \times 8 \mathrm{~m}$ parcels with lit crowns,
$100 \%$ CC, and high signal with respect to the surroundings in the co-registered near infrared (NIR) IKONOS scene. The crown structure (average height and thickness of crown) of the trees was estimated in this $8 \mathrm{~m} \times 8 \mathrm{~m}$ area. An inversion procedure led to LOP values such that the TOA reflectance value of the simulated lit crowns was equal to the observed IKONOS reflectance values. In this approach, leaf reflectance (both sides) and transmittance values were assumed equal. Moreover, LOP was given a unique spectral value for all trees in the forest plot. These two simplifying assumptions were adopted because they already led to a robust approach for biophysical parameter inversion from very high resolution imagery (Gascon et al., 2004). The shape of tree crowns was assumed ellipsoidal and leaf angle distribution was assumed spherical. Optical properties of tree trunks were taken from the ASTER database (ASTER, 2003).

\section{Methods}

\subsection{Classifiers' dissimilarity measures}

Three classifiers were selected for the performance test, namely the Minimum Distance (MD), the Maximum Likelihood (ML) and a first order Frequency-Based (FB) classifier. A key algorithmic step among these parametric classifiers is the minimization of the spectral distance in a window size of interest.

The Euclidian distance $\operatorname{ED}_{i j}=\left|\mu_{i}-\mu_{j}\right|$, where $\mu_{i}$ is a vector containing the mean spectral value of pixels in forest plot $i$, measures the spectral separation between classes $i$ and $j$ for the MD classifier. Because of the high variability of the signal in hyper-spatial imagery of forests (Gascon et al., 2004), we observed that MD discriminated classes with greater success for larger window sizes. Consequently, mean values taken for ED distance calculations were extracted from a $25 \mathrm{~m} \times 25 \mathrm{~m}$ fixed sized subplot (for reference to the high resolution of typically available sensors) of the forest plot.

The Bhattacharyya distance expresses the dissimilarity between two clusters of pixels for the ML classifier (Landgrebe, 2000 ). Here, The Bhattacharyya distance $\mathrm{BD}_{i j}$ between forest plots $i$ and $j$ seen on multi-spectral IKONOS imagery was calculated according to Landgrebe (2000):

$$
\begin{aligned}
\mathrm{BD}_{i j}= & \frac{1}{8}\left[\mu_{i}-\mu_{j}\right]^{\mathrm{T}}\left[\frac{\Sigma_{i}+\Sigma_{j}}{2}\right]^{-1}\left[\mu_{i}-\mu_{j}\right] \\
& +\frac{1}{2} \ln \frac{\left|(1 / 2)\left[\Sigma_{i}+\Sigma_{j}\right]\right|}{\sqrt{\left|\Sigma_{i}\right|\left|\Sigma_{j}\right|}}
\end{aligned}
$$

where $\mu_{i}$ contains the mean spectral value of all pixels in forest plot $i$, and $\Sigma_{i}$ is the covariance matrix of the vectors corresponding to all pixel values in forest plot $i$.

Finally, the Frequency-Based Distance (FBD) is the dissimilarity measure for the FB classifier. FBD operates, as well as BD, on all individual multi-spectral pixel values inside a forest plot. These multi-spectral values were first grouped in bins to form a multispectral histogram. The bin size was set as the sum of the IKONOS and DART noise levels, in each spectral band. The DART noise level 
was assessed as the standard deviation of the differences of reflectance values simulated with DART and with a Monte Carlo model, included in the DART model package. The Monte Carlo model is assumed to be exact, but very computer extensive which explains why it is not commonly used. Martin (2006) showed that DART relative accuracy with respect to the Monte Carlo model is better than $2 \% . \mathrm{FBD}_{i j}$ between forest plots $i$ and $j$ seen on multispectral IKONOS imagery was calculated according to Maletti et al. (2002, p. 702):

$\operatorname{FBD}_{i j}=\frac{1}{2 B} \sum_{b=1}^{B} \sum_{n=1}^{Q}\left|h_{i}[b, n]-h_{j}[b, n]\right|$

where $B$ is the number of spectral bands, $h_{i}$ is the per band normalized histogram of the pixels in forest plot $i$, and $Q$ is the number of quantization bins.

\subsection{Intra-class and inter-class studies}

ED, BD and FBD were first computed between DART-simulated and IKONOS images of the six forest plots, yielding the 'DARTIKONOS dissimilarities'. Next, the six forest plots were simulated with varying CC, LAI, and $\rho_{\mathrm{u}}$ (understory reflectance) values in order to account for the variation measured in the reference parcels. For this purpose, we selected for each forest setting the minimum and maximum CC, LAI and $\rho_{\mathrm{u}}$ values that were measured in the associated set of reference parcels. As a result, a set of eight simulations $\mathcal{S}\left(\mathrm{CC}, \mathrm{LAI}, \rho_{\mathrm{u}}\right)$ per forest setting was computed, with these three parameters equal to either the minimum or the maximum measured value. For example, $\mathcal{S}\left(\mathrm{CC}_{\min }, \mathrm{LAI}_{\max }, \rho_{\mathrm{u} \text { min }}\right)$ is one of these simulations. Distances were computed between all pairs of these eight simulations. The maximum of these distances expressed the 'intra-class dissimilarity' of a forest setting. This definition of intra-class dissimilarity was viewed as a trade off. Indeed, the calculated distances tend to overestimate intra-class variability because the impact of the CC, LAI and $\rho_{\mathrm{u}}$ extreme values on intra-class variability may be overestimated. On the other hand, they underestimate intra-class variability because the variation of other parameters such as leaf optical properties, that could not be measured were not taken into account. Confronting the DARTIKONOS dissimilarity value with the intra-class dissimilarity was a means of testing DART as a proxy for pixel value distribution of real, very high resolution IKONOS imagery.
As a second step, the same forest plots were simulated, setting viewing orientation, sun position, and atmospheric conditions to the values found in the Tancítaro area. Dissimilarities between pairs of classes, as well as intra-class dissimilarities, were calculated for each forest type, the comparison of which was aimed at determining whether forest classes were ambiguous, or separable.

\section{Results}

\subsection{Intra-class study with simulated imagery}

Figs. 4-9(d) illustrate results of 1 m-resolution DART simulations of all forest plots. Table 3 reports the computed dissimilarities corresponding to the MD, ML and FB classifiers, for the DART-IKONOS comparison of every forest type, as well as for the intra-class studies. The dissimilarities were computed for all four bands (line denominated 'all') and for each mono-spectral band. In all forests, the DART-IKONOS dissimilarity according to MD is lower than intra-class dissimilarity, indicating a good agreement (within intra-class variation) of mean values between IKONOS imagery and DART-derived imagery. Intra-class variations of mean reflectance are uneven across spectral bands: The NIR band and, to a lesser extent, the green band, generally record larger variations within a forest type than the red and blue band. This observation falls in accordance with the magnitude of absolute reflectance value of green vegetation in those spectral domains.

The similarity of pixel value distributions in DART imagery with respect to IKONOS imagery can be appreciated in Fig. 10(a-f), where histograms of corresponding scenes in the NIR band (the spectral band with the strongest dynamic range) are displayed. The DART-IKONOS dissimilarity in terms of pixel value distribution in the four-dimensional space (all four bands) was also found less than intra-class variability, as attested by the results of ML and FB classifiers in Table 3.

\subsection{Ambiguity pattern in real IKONOS imagery}

We further tested DART-simulated signals against real IKONOS signals by investigating ambiguity patterns among the three forest classes present in the Tancítaro setting. These patterns were studied using an 'ambiguity matrix', displayed in Table 4. Diagonal data (within outlined rectangles) represent the intra-class

Table 3

Spectral dissimilarity $\Delta_{\mathrm{D}, \mathrm{I}}$ between DART and IKONOS signals, and DART intra-class dissimilarity $\sigma_{\mathrm{D}}$

\begin{tabular}{|c|c|c|c|c|c|c|c|c|c|c|c|c|c|}
\hline & \multirow[t]{2}{*}{ Band } & \multicolumn{2}{|l|}{ Oak } & \multicolumn{2}{|l|}{ Pine } & \multicolumn{2}{|l|}{ Fir } & \multicolumn{2}{|l|}{ Avocado } & \multicolumn{2}{|c|}{ Tropical secondary } & \multicolumn{2}{|c|}{ Tropical primary } \\
\hline & & $\Delta_{\mathrm{D}, \mathrm{I}}$ & $\sigma_{\mathrm{D}}$ & $\Delta_{\mathrm{D}, \mathrm{I}}$ & $\sigma_{\mathrm{D}}$ & $\Delta_{\mathrm{D}, \mathrm{I}}$ & $\sigma_{\mathrm{D}}$ & $\Delta_{\mathrm{D}, \mathrm{I}}$ & $\sigma_{\mathrm{D}}$ & $\Delta_{\mathrm{D}, \mathrm{I}}$ & $\sigma_{\mathrm{D}}$ & $\Delta_{\mathrm{D}, \mathrm{I}}$ & $\sigma_{\mathrm{D}}$ \\
\hline \multirow[t]{5}{*}{ MD } & All bands & 0.3 & 1.3 & 0.3 & 1.5 & 0.4 & 1.3 & 0.2 & 1.6 & 0.4 & 1.8 & 0.5 & 1.6 \\
\hline & NIR & 0.2 & 3.0 & 0.3 & 2.4 & 0.4 & 1.8 & 0.0 & 2.2 & 0.3 & 3.2 & 0.3 & 4.2 \\
\hline & Red & 0.1 & 1.0 & 0.0 & 0.8 & 0.4 & 0.8 & 0.4 & 0.8 & 0.3 & 0.5 & 0.1 & 0.5 \\
\hline & Green & 0.4 & 1.0 & 0.5 & 2.8 & 0.1 & 1.4 & 0.4 & 2.0 & 0.7 & 2.7 & 0.6 & 1.7 \\
\hline & Blue & 0.4 & 1.4 & 0.5 & 1.2 & 0.8 & 1.1 & 0.1 & 1.2 & 0.2 & 0.9 & 0.8 & 1.0 \\
\hline \multirow[t]{5}{*}{ ML } & All bands & 0.104 & 0.328 & 0.097 & 0.132 & 0.058 & 0.138 & 0.048 & 0.081 & 0.129 & 0.257 & 0.223 & 0.259 \\
\hline & NIR & $1.7 \mathrm{E}-04$ & $3.4 \mathrm{E}-05$ & $5.7 \mathrm{E}-05$ & $6.4 \mathrm{E}-04$ & $2.3 \mathrm{E}-05$ & $9.1 \mathrm{E}-04$ & $3.6 \mathrm{E}-05$ & $2.2 \mathrm{E}-05$ & $2.5 \mathrm{E}-04$ & $2.0 \mathrm{E}-04$ & $5.2 \mathrm{E}-05$ & $7.8 \mathrm{E}-06$ \\
\hline & Red & $3.8 \mathrm{E}-06$ & $1.3 \mathrm{E}-04$ & $3.8 \mathrm{E}-05$ & $2.3 \mathrm{E}-04$ & $1.2 \mathrm{E}-04$ & $6.0 \mathrm{E}-04$ & $1.0 \mathrm{E}-04$ & $6.6 \mathrm{E}-05$ & $1.0 \mathrm{E}-05$ & $4.2 \mathrm{E}-04$ & $4.0 \mathrm{E}-05$ & $1.3 \mathrm{E}-03$ \\
\hline & Green & $1.1 \mathrm{E}-05$ & $4.2 \mathrm{E}-03$ & $1.2 \mathrm{E}-04$ & $4.3 \mathrm{E}-04$ & $5.8 \mathrm{E}-06$ & $1.8 \mathrm{E}-03$ & $1.5 \mathrm{E}-06$ & $2.0 \mathrm{E}-03$ & $1.2 \mathrm{E}-03$ & $8.4 \mathrm{E}-03$ & $4.3 \mathrm{E}-04$ & $7.6 \mathrm{E}-03$ \\
\hline & Blue & $3.4 \mathrm{E}-05$ & $4.7 \mathrm{E}-03$ & $5.3 \mathrm{E}-03$ & $9.2 \mathrm{E}-03$ & $1.1 \mathrm{E}-03$ & $1.7 \mathrm{E}-03$ & $5.5 \mathrm{E}-05$ & $4.1 \mathrm{E}-04$ & $2.6 \mathrm{E}-04$ & $5.6 \mathrm{E}-04$ & $1.4 \mathrm{E}-04$ & $1.3 \mathrm{E}-03$ \\
\hline \multirow[t]{5}{*}{ FB } & All bands & 0.26 & 0.41 & 0.31 & 0.44 & 0.27 & 0.40 & 0.23 & 0.45 & 0.17 & 0.33 & 0.37 & 0.44 \\
\hline & NIR & 0.35 & 0.33 & 0.25 & 0.37 & 0.28 & 0.38 & 0.35 & 0.34 & 0.35 & 0.31 & 0.44 & 0.40 \\
\hline & Red & 0.28 & 0.36 & 0.39 & 0.42 & 0.20 & 0.29 & 0.23 & 0.39 & 0.04 & 0.29 & 0.41 & 0.47 \\
\hline & Green & 0.27 & 0.55 & 0.31 & 0.42 & 0.15 & 0.55 & 0.13 & 0.65 & 0.23 & 0.57 & 0.25 & 0.62 \\
\hline & Blue & 0.14 & 0.60 & 0.27 & 0.56 & 0.44 & 0.58 & 0.21 & 0.55 & 0.07 & 0.23 & 0.37 & 0.42 \\
\hline
\end{tabular}

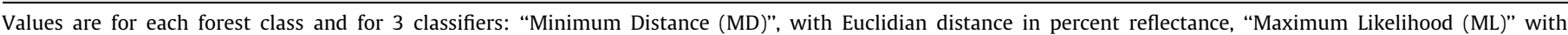
Bhattacharyya distance, and "Frequency-Based (FB)", with Density function-based distance. 

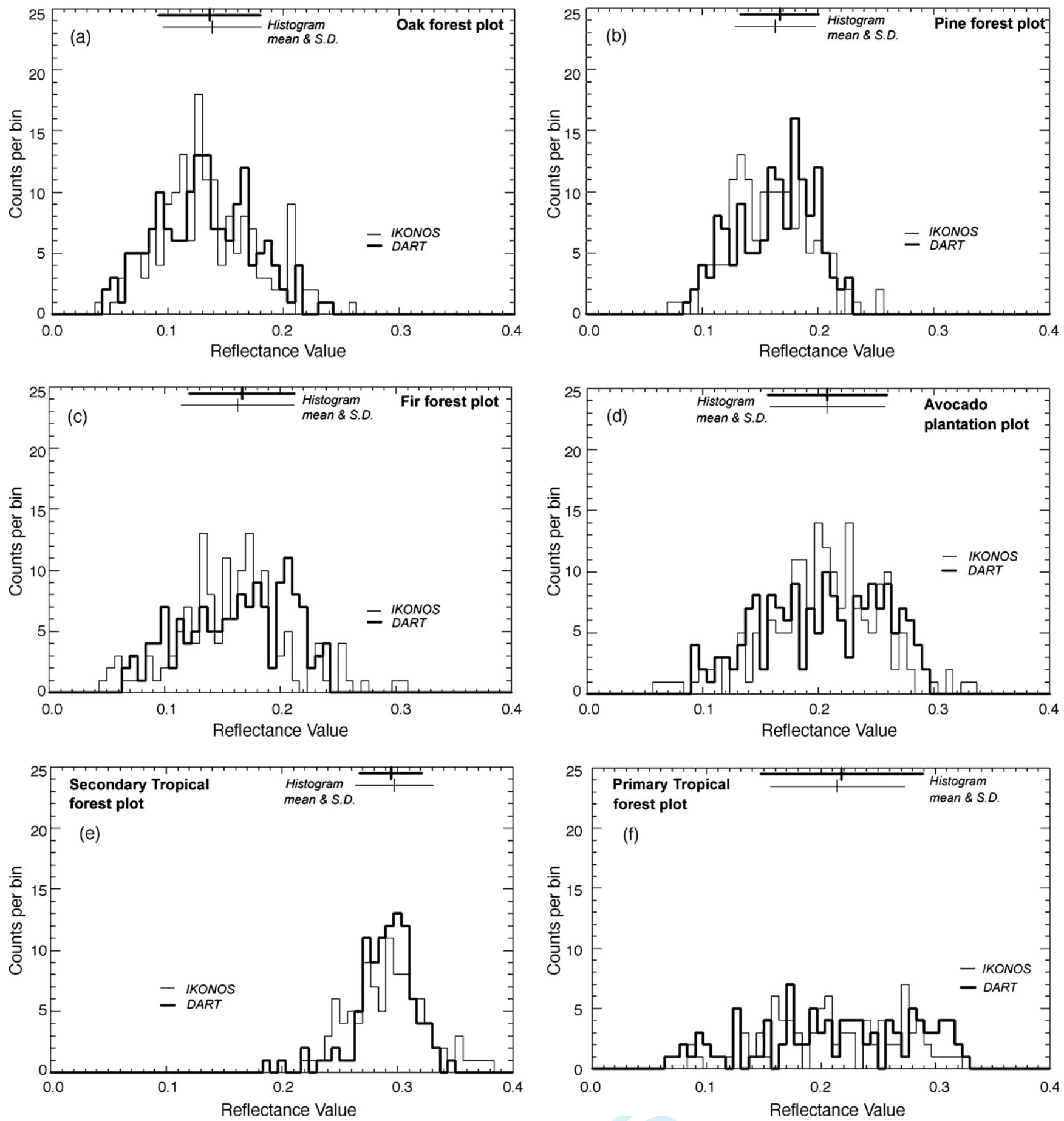

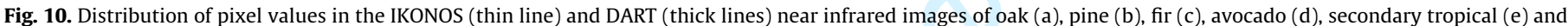
primary tropical (f) forests. Histogram mean and standard deviation are shown in the top part of each graph.

dissimilarity for each forest type (information contained in Table 3). Off-diagonal data give, for all classifiers, dissimilarity values between pairs of classes, computed from the real IKONOS imagery (upper right part of the matrix) or from the DARTsimulated imagery (bottom left part of the matrix). Dissimilarity values from DART-derived information (bottom left part) were found highly correlated with dissimilarity values computed from the real IKONOS imagery (upper right part), with the highest correlations recorded when all bands are considered $\left(r^{2}=0.98\right.$ for $\mathrm{MD}, r^{2}=0.99$ for ML and $r^{2}=0.94$ for $\mathrm{FB}$ ).
Off-diagonal (inter-class) dissimilarities, when compared to intra-class dissimilarities on the diagonal of Table 4, provide the information of whether the forest types are ambiguous or separable. For example, pine was found ambiguous with fir and avocado forests using MD on all bands, whereas only pine and fir forests were ambiguous with ML. Indeed, MD and ML dissimilarities (all bands) for 'pine-fir' are 0.3 and 0.121 (bottom left part of the matrix), or 0.6 and 0.074 (upper right part of the matrix), superior to fir intra-class dissimilarities 1.3 (MD) and 0.138 (ML), respectively. Conversely, the fir and pine forests were separable (as 
Table 4

Ambiguity matrix for the pine, fir and avocado classes in the IKONOS Tancítaro image

\begin{tabular}{|c|c|c|c|c|c|c|c|c|c|c|}
\hline \multirow[b]{2}{*}{ Forest: } & \multirow[b]{2}{*}{ Band: } & \multicolumn{3}{|l|}{ Pine } & & \multicolumn{3}{|c|}{ Avocado } \\
\hline & & $\mathrm{MD}$ & ML & FB & $\mathrm{MD}$ & ML & FB & $\mathrm{MD}$ & ML & FB \\
\hline \multirow{5}{*}{ Pine } & All bands & 1.5 & 0.132 & 0.44 & 0.6 & 0.074 & 0.48 & 1.5 & 0.565 & 0.67 \\
\hline & NIR & 2.4 & $6.4 \mathrm{E}-04$ & 0.37 & 0.1 & $9.2 \mathrm{E}-04$ & 0.48 & 4.0 & 7.9E-03 & 0.67 \\
\hline & Red & 0.8 & $2.3 \mathrm{E}-04$ & 0.42 & 1.0 & $2.6 \mathrm{E}-03$ & 0.60 & 0.6 & $4.3 \mathrm{E}-03$ & 0.88 \\
\hline & Green & 2.8 & $4.3 \mathrm{E}-04$ & 0.42 & 0.8 & $2.2 \mathrm{E}-03$ & 0.57 & 0.8 & 8.8E-04 & 0.45 \\
\hline & Blue & 1.2 & $9.2 \mathrm{E}-03$ & 0.56 & 0.4 & $1.2 \mathrm{E}-03$ & 0.26 & 0.7 & $4.2 \mathrm{E}-03$ & 0.69 \\
\hline \multirow{5}{*}{ Fir } & All bands & 0.3 & 0.121 & 0.51 & 1.3 & 0.138 & 0.40 & 2.3 & 1.294 & 0.77 \\
\hline & NIR & 0.4 & $2.4 \mathrm{E}-03$ & 0.58 & 1.8 & $9.1 \mathrm{E}-04$ & 0.38 & 4.5 & $2.5 \mathrm{E}-03$ & 0.67 \\
\hline & Red & 0.6 & $4.9 \mathrm{E}-03$ & 0.60 & 0.8 & $6.0 \mathrm{E}-04$ & 0.29 & 2.0 & $3.2 \mathrm{E}-03$ & 0.70 \\
\hline & Green & 0.3 & $2.3 \mathrm{E}-03$ & 0.58 & 1.4 & $1.8 \mathrm{E}-03$ & 0.55 & 1.6 & 4.6E-03 & 0.80 \\
\hline & Blue & 0.1 & $1.3 \mathrm{E}-03$ & 0.29 & 1.1 & 1.7E-03 & 0.58 & 1.1 & $8.2 \mathrm{E}-03$ & 0.91 \\
\hline \multirow{5}{*}{ Avocado } & All bands & 1.6 & 0.607 & 0.62 & 1.9 & 1.868 & 0.81 & 1.6 & 0.081 & 0.45 \\
\hline & NIR & 4.1 & $2.3 \mathrm{E}-03$ & 0.67 & 4.1 & 2.7E-03 & 0.65 & 2.2 & $2.2 \mathrm{E}-05$ & 0.34 \\
\hline & Red & 0.6 & $2.6 \mathrm{E}-03$ & 0.68 & 1.2 & $2.6 \mathrm{E}-03$ & 0.74 & 0.8 & $6.6 \mathrm{E}-05$ & 0.39 \\
\hline & Green & 1.6 & $3.7 \mathrm{E}-03$ & 0.82 & 1.9 & $1.1 \mathrm{E}-02$ & 0.97 & 2.0 & $2.0 \mathrm{E}-03$ & 0.65 \\
\hline & Blue & 0.2 & 7.3E-04 & 0.32 & 0.4 & $6.0 \mathrm{E}-03$ & 0.87 & 1.2 & 4.1E-04 & 0.55 \\
\hline
\end{tabular}

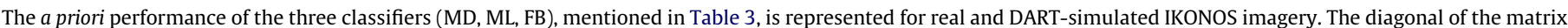

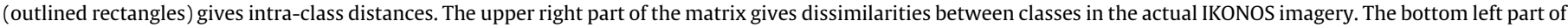
the matrix gives dissimilarities between forest classes in the corresponding DART-simulated imagery.

well as the other classes) for the FB classifier, since off-diagonal figures 0.51 or 0.48 are larger than diagonal figures 0.44 (pine intra-class) and 0.40 (fir intra-class). BD expresses a distance between multidimensional distributions assuming a Gaussian shape (Kailath, 1967) while FBD, based on the density function, relies on the actual values of the distribution, thereby reflecting dissimilarities with more robustness. Altogether, the same ambiguity pattern was found, using all bands, among the three classes present on the Tancítaro image, whether using real IKONOS or DART-derived dissimilarity values. This finding, together with the high correlation registered between IKONOS-based and DARTbased dissimilarities, provided some confidence for extending the ambiguity study among all six forest classes on a common, simulated environment.

\subsection{Ambiguities among all forest types in DART simulations}

DART simulations of all forest plots were carried out in the 'Tancítaro' setting (the natural setting of the pine, fir and avocado classes). Table 5 shows mean reflectance values for all simulations, and one 'ambiguity matrix' per classifier. These matrices are constructed the same way as Table 4, but they contain dissimilarities calculated for all four bands only. Figures in shadowed boxes indicate cases where classes are ambiguous (i.e., inter-class dissimilarity is smaller than intra-class dissimilarity).

The oak forest and the secondary tropical forest were separable from the other forest types by all classifiers. In both cases, the stand structure makes them appear clearly distinct from other forests. The signal of the low LAI oak forest is largely influenced by the understory condition, as illustrated by the mean visible and NIR reflectance values in Table 5, relatively distinct from values of other forest types. Besides, a smooth canopy (see Fig. 8a) and very high crown cover (Table 1 ) characterize the secondary tropical forest. The very reduced shadow area inferred by these characteristics causes a bright signal compared to other forest canopies, as illustrated, for example, by the elevated NIR mean reflectance (Table 5).

Most pairs involving other classes (five pairs in total), however, are ambiguous for MD. In the four spectral bands considered, the MD discrimination power in a $25 \mathrm{~m}$ window size appears to be limited to oak and secondary tropical forests. Instead, pine and primary tropical forests are confounded with three other classes each. The poor discrimination power of MD on quite distinct forests is not surprising. Indeed, most studies focussed on forest classification do not rely on minimum distance between mean pixel values, but instead on maximum likelihood (e.g. Wang et al., 2004) or more sophisticated strategies (e.g. Magnussen et al., 2004).

Neither MD nor ML could separate fir from pine forest. Besides being both conifer forests for which no successful attempt of classification was found in the literature, the present pine and fir forest stands possess close structural characteristics (relatively similar CC and LAI; see Table 1). Moreover, fir and pine forest stands are characterized by low to moderate LAI, which implies that the understory, partially covered with brownish needle litter in both cases, has a strong influence on the canopy reflectance. However, FB, due to its better sensitivity to forest stand structure, could separate fir from pine forest. Finally, the avocado plantation is confounded with the primary tropical forest for all classifiers, presumably because the reflectance of both types of forest is governed by a deep canopy and a similar shadow area.

\subsection{Relating ambiguities to confusions in the NFI map assessment}

With the purpose of understanding the role of an ambiguity study in the context of real map production, we confronted the ambiguity pattern with confusion estimates of the NFI map from a previous study. Table 6 contains a confusion matrix extracted from the accuracy assessment of the NFI map at community level over three large areas $\left(8306 \mathrm{~km}^{2}\right.$ in total, see Couturier et al., in press) containing the 3 sites of this paper. Each forest stand in our ambiguity study is included in a class of that matrix (for example, the avocado plantation is included in the 'Perennial Crop' class).

According to Table 6, major confusions did occur between pine and perennial crop: the confused area summed up to $47.3 \mathrm{~km}^{2}$ versus $100.9 \mathrm{~km}^{2}$ of pine forests effectively mapped as pine. The confusion was entirely observed in the Tancitaro area where $90 \%$ of perennial crop is avocado plantation. This confusion actually corresponds to an ambiguity between pine and avocado plantation for MD (Table 5). However, Table 5 also indicates that this pair of 
Table 5

Matrix of classifier's theoretical performance for all forest classes

\begin{tabular}{|c|c|c|c|c|c|c|c|}
\hline \multirow{5}{*}{$\begin{array}{l}\text { Mean } \\
\text { Reflectance }\end{array}$} & & Oak & Pine & Fir & Avocado & $\begin{array}{l}\text { Tropical } \\
\text { Second. }\end{array}$ & $\begin{array}{l}\text { Tropical } \\
\text { Primary }\end{array}$ \\
\hline & NIR & 12.7 & 16.7 & 16.3 & 20.8 & 29.3 & 18.9 \\
\hline & Red & 5.7 & 4.3 & 3.7 & 4.9 & 4.9 & 3.9 \\
\hline & Green & 6.7 & 4.9 & 4.7 & 6.5 & 6.4 & 6.1 \\
\hline & Blue & 8.2 & 7.1 & 7.0 & 7.3 & 8.7 & 7.4 \\
\hline \multirow{9}{*}{$\begin{array}{l}\text { Minimum } \\
\text { Distance } \\
\text { Classifier }\end{array}$} & & Oak & Pine & Fir & Avocado & $\begin{array}{l}\text { Tropical } \\
\text { Second. }\end{array}$ & $\begin{array}{l}\text { Tropical } \\
\text { Primary }\end{array}$ \\
\hline & Oak & 1.3 & & & & & \\
\hline & Pine & 2.1 & 1.5 & & & & \\
\hline & Fir & 2.2 & 0.3 & 1.3 & & & \\
\hline & Avocado & 2.5 & 1.6 & 1.9 & 1.6 & & \\
\hline & Trop. Second. & 4.6 & 4.1 & 4.4 & 2.5 & 1.8 & \\
\hline & Trop. Primary & 2.4 & 1.0 & 1.2 & 0.9 & 3.2 & 2.1 \\
\hline & Oak & 0.273 & & & & & \\
\hline & Pine & 1.707 & 0.132 & & & & \\
\hline \multirow{4}{*}{$\begin{array}{l}\text { Maximum } \\
\text { Likelihood } \\
\text { Classifier }\end{array}$} & Fir & 1.523 & 0.121 & 0.138 & & & \\
\hline & Avocado & 0.914 & 0.607 & 1.868 & 0.081 & & \\
\hline & Trop. Second. & 0.645 & 1.872 & 1.300 & 0.378 & 0.267 & \\
\hline & Trop. Primary & $\underline{0.786}$ & 0.255 & 1.609 & 0.137 & 0.303 & 0.209 \\
\hline \multirow{6}{*}{$\begin{array}{l}\text { Frequency } \\
\text { Based } \\
\text { Classifier }\end{array}$} & Oak & 0.42 & & & & & \\
\hline & Pine & 0.79 & 0.44 & & & & \\
\hline & Fir & 0.78 & 0.51 & 0.40 & & & \\
\hline & Avocado & 0.73 & 0.62 & 0.81 & 0.45 & & \\
\hline & Trop. Second. & 0.64 & 0.70 & 0.91 & 0.56 & 0.33 & \\
\hline & Trop. Primary & 0.60 & 0.58 & 0.75 & 0.44 & 0.51 & 0.45 \\
\hline
\end{tabular}

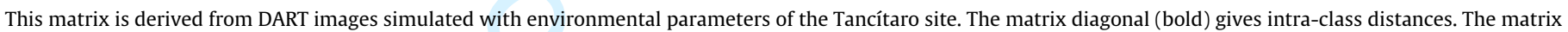

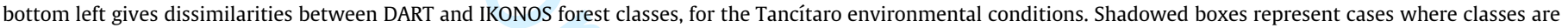
ambiguous (i.e., where inter-class dissimilarity value is smaller than intra-class dissimilarity value).

classes is separable using ML and FB on 4 m-IKONOS imagery. This result could constitute an incentive towards diminishing NFI map confusions using finer resolution, eventually with ML or FB classifiers. According to Table 6 , fir forests were somewhat confounded with pine forests $\left(1.2 \mathrm{~km}^{2}\right.$ confused area versus $11.2 \mathrm{~km}^{2}$ of fir forest mapped as fir). The two classes were also reported ambiguous using MD. The ambiguity is probably more pronounced than the previous case since this time, only the FB classifier (and not ML) could separate the pair of class at $4 \mathrm{~m}$ resolution. The latter information might be interesting in the perspective of improving the accuracy of the map on the reduced area where fir forests occur.

Next, $9.4 \mathrm{~km}^{2}$ of land was subject to a confusion between secondary and primary tropical forest, against $55.7 \mathrm{~km}^{2}$ of correctly mapped secondary tropical forest. However, this pair of classes seemed to cause no separability problem on the IKONOS data (no ambiguity for any of the classifiers). The structure of the secondary forest stand studied in this paper has age-specific, homogeneous characteristics compared to the variety of common secondary forests patches, the most mature of which are certainly more difficult to distinguish from primary forest. A limitation of this method is therefore the correct representation of the diversity within a class. For example, forest plots of various age successions would be necessary to calculate secondary forest intra-class variation. Besides, no confusion was recorded between secondary tropical forests and other classes, coinciding with the null ambiguity in our study, although anyways little interface existed between secondary forest and those classes on the large area where the map had been assessed.

Only a small confusion pattern was detected (Table 6) between perennial crop and primary tropical forest $\left(11.8 \mathrm{~km}^{2}\right.$ of confused area versus $337.2 \mathrm{~km}^{2}$ of correctly mapped primary tropical forest), whereas avocado plantation was systematically confused with primary tropical forest in our experiment. Indeed, the NFI confusion occurred in the region of Los Tuxtlas and concerned shaded coffee or mango plantations and not avocado, so the results

Table 6

NFI confusion matrix of six forest classes over three zones containing the study sites

\begin{tabular}{|c|c|c|c|c|c|c|}
\hline & Oak & Pine & Fir & Perennial crop & Tropical secondary & Tropical primary \\
\hline Oak & 86.04 & & & & & \\
\hline Pine & 1.89 & 100.88 & & & & \\
\hline Fir & 0 & 1.16 & 11.17 & & & \\
\hline Perennial crop & 0.06 & 47.27 & 0 & 348.04 & & \\
\hline Tropical Secondary & 0 & 0 & 0 & 0 & 55.69 & \\
\hline Tropical primary & 0 & 0.06 & 0 & 11.84 & 9.35 & 337.19 \\
\hline
\end{tabular}

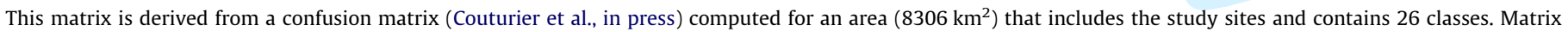

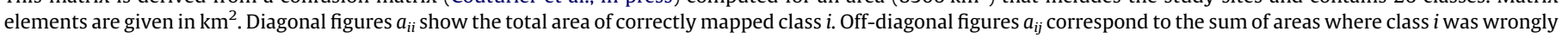
mapped as class $j$ and where class $j$ was wrongly mapped as class $i$. 
of our experiment cannot be applied to the Los Tuxtlas region, and further work should concern shaded coffee or mango plantations.

A small confusion pattern was also detected between oak and pine forests $\left(1.9 \mathrm{~km}^{2}\right.$ confusion area versus $86.0 \mathrm{~km}^{2}$ of oak forests) whereas pine and oak forests are clearly separated in the ambiguity study. In reality, oak forests, dominated by $Q$. deserticola, may occur close to pine forests in the fringe between sub-humid temperate and tropical dry climate zones. However, the interface between oak and pine forests is certainly more abundant within the temperate zone of the state of Michoacán, where the structure of oak forests (taller and rounder crowns) and species dominance are very distinct to the ones of the forest studied in this work, and probably more prone to ambiguities with pine forests. Thus, the nonambiguity results from this study should not be generalized to the entire 'oak' forest type in the NFI classification system; instead, this experiment ought to be extended to oak stands situated in subhumid temperate conditions before concluding on a priori classification ambiguities of the forest inventory in that eco-zone. The oak forest had very little interface with the remaining set of classes on the map, resulting in null or almost null confusion with these other classes.

A step further into the exploration of ambiguity patterns, also possible with this methodology, would consist in modelling mixed forests, characterized by the physiognomic dominance of both conifers and broadleaf species, because mixed forest is also a major forest class in the sub-humid temperate eco-zone.

\section{Discussion}

\subsection{The database on forest ambiguities}

This work aims at contributing to the following research question: given a set of forest classes, which remote sensor and automatic classification technique are optimal to generate a reasonably accurate map? The usual approach for forest mapping with remote-sensing imagery is to directly apprehend inter-class and intra-class signals from an image of the sensor at hand, and test various classifying techniques using a set of reference field data. A drawback of this approach is that any updating of the map based on a new image involves repeating the tests and updating the field data for verification, because the new image is characterized by new environmental conditions, or was taken by a new sensor.

It is argued in this work that a database containing structural properties of forests at plot scale could yield a systematic a priori estimation of ambiguities between pairs of classes. This database could constitute a useful management tool for forest mapping/ monitoring. Indeed, once validated, the modelling approach offers predictive capabilities on new remote-sensing supports and environmental conditions. However, for calibration purposes, this method requires several optical measurements on the ground (reference sites, soil and eventually leaf optical properties). Commercial radio-spectrometers are usually available in the visible-mid infrared spectral range, meaning that this method is readily applicable only for this spectral range.

\subsection{Field data collection and resolution issues}

Due to the highly heterogeneous nature of forests, the 3Dmodelling approach we propose demands at first a wealth of ground measurements, but then no repetition of such field data should be needed to update results to future conditions. Typically, high resolution $(20-30 \mathrm{~m})$ resolution imagery is widely used for forest mapping. However, at such a resolution, an enormous amount of crown-scale field data would have been needed, per forest type, to directly compare simulated to real imagery in a statistically meaningful way (for example, 50 Landsat pixels would require the detailed survey of 4.5 ha!). Taking advantage of the availability of very high resolution imagery (1-5 m resolution), this work proposes to model reflectance distribution of forests with field data gathered from plot sizes typical of forest inventory surveys $(40 \mathrm{~m} \times 40 \mathrm{~m}$ or $50 \mathrm{~m} \times 50 \mathrm{~m})$. Additionally, in the estimation of intra-class variation, the modelling approach is useful to minimize the collection of field data. For example, only CC and LAI were measured on the reference parcels and no additional detailed inventory was needed. Still, a limitation of the method may be the reduced number of points from typical forest plot sizes, for the construction of a histogram the sufficiently representative of a class. Indeed, the calculations of BD and FBD are based on the intersection of histograms, e.g. the count of coinciding bins in the feature space. If the histograms are constructed with a small number of points (few filled bins in the feature space), the intersection of histograms may be underestimated. This limitation is more sensitive for the construction of multidimensional histograms, which requires more bins than a one-dimensional histogram. Theoretically, the method could be applicable to hyperspectral data with hyperspectral parametric classification techniques. However, the limited number of forest plot points hinders histogram construction in the hyperspectral space. Therefore, a pre-processing step for reducing the spectral dimension of the imagery (e.g. principal component analysis) would be recommendable in this case before using classifiers based on BD and FBD.

Although the texture of $1 \mathrm{~m}$-resolution imagery is sometimes used as an auxiliary band to improve discrimination of forests or forest stand structures (Wang et al., 2004; Colombo et al., 2003), only the $4 \mathrm{~m}$-resolution IKONOS data was retained in this study. Indeed, the simplifying assumptions used in the DART model for forest canopy (e.g. crowns modelled by ellipsoids) limited the resemblance of DART-simulated imagery with real IKONOS imagery at $1 \mathrm{~m}$ resolution; this phenomenon is especially visible for primary tropical forest (see differences in the appearance of emergent crowns between Fig. 9(e) and (f)). In fact, preliminary tests demonstrated notable differences between first order texture channels of simulated versus real imagery, which limited the usefulness of our modelling approach at $1 \mathrm{~m}$ resolution. This problem originates from the DART module that simulates 3D forest covers, and not from the radiative transfer module that can work with any $3 \mathrm{D}$ environment. In order to solve this problem, CESBIO is developing an interface between the DART radiative transfer module and a 3D model dedicated to the simulation of realistic forest covers. In spite of this limitation, a result of this study is that DART simulation could approach the $4 \mathrm{~m}$ real signal (multispectral IKONOS image) more accurately than intra-class signal variation, even for tropical forest stands (Table 3 ).

\subsection{Structural and optical properties of the forest}

Inter-class dissimilarities were measured on both simulated and real imagery and both quantities compared favourably (Table 4). Intra-class variation was modelled for forest stand structure on relatively flat terrain, which implies that the ambiguity results of this study only apply to forest classes on relatively flat terrain. The intra-class variation also compared favourably to the intra-class variation that we observed on the reference parcels (also on flat terrain) of the real imagery. However, classification exercises on large areas with pronounced relief are affected by more reflectance variability than measured in this study (greater intra-class variation), and subject to more ambiguities among classes. Further research is under way to model 
and study the same forest types on steep terrain, since much of the forest outside the plots investigated occurred on micro relief or pronounced slopes, in which case the forest stand structure was distinct. This additional work may open the way to a priori ambiguity measures on the entire forest mass of the IKONOS image. In this context, the DART model is useful because it can operate on 3D landscapes with topography.

Optical properties of leaves, not available on existing databases, were inferred from the imagery. We did not account for the fact that leaf optical properties display spatial variations, even within individual tree crowns. Moreover, we did not account for horizontal variations of leaf volume density within individual tree crowns. The radiative transfer module of DART can account for these 3D variations. However, we could not measure them and, thus, use this information in the DART simulations.

\subsection{Type of classifier}

In spite of forest stands taxonomically very distinct, MD performed poorly at distinguishing various class pairs for a $25 \mathrm{~m}$ window size. For smaller window sizes, we attested that MD performed worse due to a very large intra-class signal (forest heterogeneity); however, for bigger window sizes, intra-class mean value variation is smaller and MD would probably have performed equal or better, although this implies mapping at coarser resolutions. Indeed, many forest classification studies recommend to low pass filter the high resolution $(20-30 \mathrm{~m})$ imagery prior to classification; for example, in recent studies, Salovaara et al. (2005) smoothened the Landsat image with a $5 \times 5$ pixel window (i.e., $150 \mathrm{~m} \times 150 \mathrm{~m}$ ), and Arroyo-Mora et al. (2005) smoothened it with a $3 \times 3$ pixel window (i.e., $90 \mathrm{~m} \times 90 \mathrm{~m}$ ). Reaching these window sizes with our approach is possible, but requires the survey of larger plots, and the integration of scenarios with uneven topography.

Only two cases were ambiguous using the ML classifier versus five cases using MD. This study confirms ML, which takes into account the pixel value distribution across bands, as a reasonably good classifier of forests on multi-spectral IKONOS imagery. This was illustrated by Wang et al. (2004) on taxonomically close forests. When the reflectance distribution deviates too much from normality, FB classifier might reduce ambiguities found using ML. An example in this study may have been the fir forest, whose NIR reflectance distribution tends to deviate from normality (Fig. 10c), and was confounded with pine forest using ML whereas the pair of classes was separable using FB.

\subsection{Scaling up to confusions in the NFI map}

Some ambiguity results may have given insights on possible causes for confusions in the NFI map, as reported in the previous section. These insights, however, have to be placed in their context since this study presents cases of automatic classification applied to a reduced set of spectral bands, as compared to those of the Landsat sensor, support of the NFI map production. The classification strategy for NFI map production relied on visual interpretation of Landsat colour composites printed at scale 1:125,000 (see Mas et al., 2002). The visual classification, because of synoptic abilities of the human eye, is certainly more successful than MD applied to the four IKONOS bands, which only correspond to the Blue, Green, Red and NIR Landsat bands. Another limitation to this comparison exercise is the necessary information on other possible sources of errors in the map such as geometric or scaleinduced.

Besides, as evident from the confrontation of ambiguity and confusion matrices, many classes of this pilot study are not comparable to the classes at community level of the NFI map, in the sense that they are contained in taxonomically larger classes. Surveys need to be done in all forest stands representative of the forest class on the map, before the ambiguity study may apply to the entire class. In this sense, a limitation of this approach, apart from shortcomings of the model itself in approximating real forest imagery, is that a certain amount of sample forest stands is needed before the database can serve as a performance test for an entire classification system.

However, the exercise can virtually be extended to any userdefined forest class (whether physiognomic, taxonomic or crown coverage-defined). An advantage of this method is that the database benefits cumulatively from any additional input of classes. Additional input in the database improves the accuracy of the estimates and/or the extent of its applicability to new forest classes, whereas the sum of previous empirically based classification methods hardly tells about the outcome of a classification in a new setting with a new remote sensor.

\section{Conclusion}

This research sets a model-based methodology for studying ambiguity patterns among forest types on satellite imagery. The methodology was applied to multi-spectral IKONOS imagery on six forest stands pertaining to community level classes of the Mexican National Forest Inventory. First, the DART model was successfully tested against the real IKONOS image on each forest plot in the sense that the dissimilarity between DART and IKONOS images was found within intra-class variation in the six forest types. Consequently, DART was used as a proxy for IKONOS imagery in order to estimate ambiguity among all forest classes.

As expected, a poor discrimination power was usually observed with MD for a $25 \mathrm{~m}$ window size. This is coherent with the fact that the minimum distance strategy, confronted with very high intraclass variations, is not used for forest classification but rather for more general land cover classification. Instead, in most cases, the distinct forest types were found separable by the ML and FB classifiers.

Low LAI oak forests appeared very dissimilar to other forests owing to the strong understory influence on the reflectance. The secondary tropical forest stand appeared very bright with respect to other forests because of its smooth canopy and absence of gaps. The plots of pine and fir forests were ambiguous for MD and ML on real IKONOS imagery. However, the FB classifier, probably because it better accounts for the reflectance value distribution, could separate both forests. Conversely, avocado plantation and primary tropical forest were ambiguous for all classifiers, presumably because their reflectance is governed by a deep canopy and a similar shadow area.

The confrontation of these results with the accuracy assessment of the NFI map stressed the need to extend the approach to more forest stands in the perspective of testing the classification scheme of the NFI. Some practical limitations of the approach are related to the difficulty in modelling very high resolution imagery and in incorporating the complexity of optical properties. However, improvements are technically feasible and under development. The methodology described is readily applicable to multi-spectral imagery in the visible-mid infrared range.

Considering the above, this methodology is to be extended to other forest stands, and the results are to be compared with classification accuracy results on satellite imagery. The perspective of this research is to predict confusions in forest maps, in function of the type of classifier and the taxonomic resolution of the map. In this sense, 3D modeling could be a valuable management tool for better assessing the expected accuracy of automatic classification 
of forest types of interest, as a function of the characteristics of the remote-sensing system and of the experimental configuration of the image acquisition. Consequently, it could be of help in the decision process related to buying satellite imagery and/or classification software.

\section{Acknowledgments}

This research and the acquisition of IKONOS imagery were funded by CONACYT (the national science and technology board in Mexico) under project number 38965T. Field work was carried out with a local team composed of biologists, botanists and technical foresters in the community of San Juan Parangaricutiro, Tancítaro, in the ejido village of La Perla de San Martin, Los Tuxtlas, and in the El Cerro village near to the Cuitzeo lake. For the completion of this work, special thanks are due to Isela Zermeño Hernández, Moisés Méndez Toribio, Rafael Pompa Vargas and Alfredo Patiño Siciliano. We are indebted to the entire team that develops the DART model.

\section{References}

Arroyo-Mora, J.P., Sánchez-Azofeifa, G.A., Kalacska, M.E.R., Rivard, B., Calvo-Alvarado, J.C., Janzen, D.H., 2005. Secondary forest detection in a neotropical dry forest landscape using Landsat 7 ETM+ and IKONOS imagery. Biotropica 37 (4) 497-507.

ASTER, Spectral database, NASA/JPL, http://speclib.jpg.nasa.gov, 2003.

Baban, S.M.J., Kamaruzaman, W.Y., 2001. Mapping land use/cover distribution on a mountainous tropical island using remote sensing and GIS. International Journal of Remote Sensing 22 (10), 1909-1918.

Benjamin, S., White, J.M., Argiro, D., Lowell, K., 1996. In: Scott, H.M., Tear, T.H., Davis, F.W. (Eds.), Gap Analysis-A Landscape Approach to Biodiversity Planning. American Society for Photogrammetry and Remote Sensing, Bethesda, MD, pp. 279288.

Berk, A., Bernstein, L.S., Robertson, D.C., 1989. MODTRAN: A Moderate Resolution Model for LOWTRAN7, GL-TR-89-0122. Geophysical Laboratory, Bedford, MA, USA, 38 pp.

Colombo, R., Bellingeri, D., Fasolini, D., Marino, C.M., 2003. Retrieval of leaf area index in different vegetation types using high resolution satellite data. Remote Sensing of Environment 86, 120-131.

Courbaud, B., de Coligny, F., Cordonnier, T., 2003. Simulating radiation distribution in a heterogeneous Norway spruce forest on a slope. Agricultural and Forest Meteorology 116 (1), 1-18.

Couturier, S., Mas J.F., López E., Benítez J., Tapia V., A. Vega. Accuracy assessment of the Mexican National Forest Inventory map: a study in four eco-geographical areas. Singapore Journal of Tropical Geography, in press.

Disney, M., Lewis, P., Saich, P., 2006. 3D modelling of forest canopy structure for remote sensing simulations in the optical and microwave domains. Remote Sensing of Environment 100, 114-132.

Fassnacht, K.S., Cohen, W.B., Spies, T.A., 2006. Key issues in making and using satellite-based maps in ecology: a primer. Forest Ecology and Management 222, $167-181$.

Gascon, F., Gastellu-Etchegorry, J.P., Lefèvre-Fonollosa, M.J., Dufrêne, E., 2004 Retrieval of forest biophysical variables by inverting a 3-D radiative transfer model and using high and very high resolution imagery. International Journal of Remote Sensing 25 (12), 5601-5616.

Gastellu-Etchegorry, J.P., Martin, E., Gascon, F., 2004. DART: a 3-D model for simulating satellite images and surface radiation budget. International Journal of Remote Sensing 25 (1), 75-96.

Gastellu-Etchegorry, J.P., Trichon, V., 1998. A modelling approach of PAR environment in a tropical rain forest in Sumatra: application to remote sensing. Ecological Modelling 108, 237-264.

Gastellu-Etchegorry, J.P., Hapke handbook, CESBIO, Toulouse, France (http:// www.cesbio.ups-tlse.fr), 15 pp., 2006.

Gemmel, F., Varjo, J., 1999. Utility of reflectance model inversion versus two spectral indices for estimating biophysical characteristics in a boreal forest test site. Remote Sensing of Environment 68, 95-111.

Goel, N.S., Thompson, R.L., 2000. A snapshot of canopy reflectance models, and a universal model for the radiation regime. Remote Sensing Reviews 18, 197-225.

Hapke, B., 1993. Theory of Reflectance and Emittance Spectroscopy. Cambridge, 455 pp.

Jonckheere, I., Fleck, S., Nackaerts, K., Muys, B., Coppin, P., Weiss, M., Baret, F., 2004. Review of methods for in situ leaf area index determination, Part I. Theories, sensors and hemispherical photography. Agricultural and Forest Meteorology $121,19-35$.

Kailath, T., 1967. The divergence and Bhattacharyya distance measures in signal selection. IEEE Transactions in Communication Theory 15, 152-160.
Laba, M., Gregory, S.K., Braden, J., Ogurcak, D., Hill, E., Fegraus, E., Fiore, J., DeGloria, S.D., 2002. Conventional and fuzzy accuracy assessment of the New York Gap Analysis Project land cover map. Remote Sensing of Environment 81, 443-455.

Landgrebe, D.A., 2000. Information extraction principles and methods for multispectral and hyperspectral data. In: Chen, C.H. (Ed.), Information Processing for Remote Sensing. World Scientific Publishing Co., Inc., River Edge, NJ. USA, p. 600 .

Lira, J., Maletti, G., 2002. A supervised contextual classifier based on a region-growth algorithm. Computers \& Geosciences 28, 951-959.

Lu, D., Moran, E., Batistella, M., 2003. Linear mixture model applied to Amazonian vegetation classification. Remote Sensing of Environment 87, 456-469.

Lu, D., 2005. Integration of vegetation inventory data and Landsat image for vegetation classification in the western Brazilian Amazon. Forest Ecology and Management 213, 369-383.

Magnussen, S., Boudewyn, P., Wulder, M., 2004. Contextual classification of Landsat TM images to forest inventory cover types. International Journal of Remote Sensing 25 (12), 2421-2440.

Maletti, G., Ersbøll, B., Conradsen, K., 2002. A contextual classifier that only requires one prototype pixel for each class. IEEE Transactions on Nuclear Science 49 (3), 700-706.

Martin, E. DART: Modèle 3D Multispectral et inversion d'images optiques de satellite-application aux couverts forestiers. PhD Thesis. Paul Sabatier University, Toulouse, France. 195pp., 2006.

Mas, J.F., Ramírez, I., 1996. Comparison of land use classifications obtained by visual interpretation and digital processing. ITC Journal 3 (4), 278-283.

Mas, J.F., Velázquez, A., Palacio-Prieto, J.L., Bocco, G., Peralta, A., Prado, J., 2002. Assessing forest resources in Mexico: wall-to-wall land use/cover mapping. Photogrammetric Engineering and Remote Sensing 68 (10), 966-969.

North, P.R.J., 1996. Three-dimensional forest light interaction model using a Monte Carlo method. IEEE Transactions on Geoscience and Remote Sensing 34 (4), 946-956.

Palacio-Prieto, J.L., Bocco, G., Velázquez, A., Mas, J.F., Takaki-Takaki, F., Victoria, A., Luna-González, L., et al., 2000. La condición actual de los recursos forestales en México: resultados del Inventario Forestal Nacional 2000. Investigaciones Geográficas 43, 183-202.

Pinty, B., Verstraete, M.M., 1991. Extracting information on surface properties from bi-directional reflectance measurements. Journal of Geophysical Research 96, 2865-2874.

Pinty, B., Verstraete, M.M., Gobron, N., 1998. The effect of soil anisotropy on the radiance field emerging from vegetation canopies. Geophysical Research Letters 25 (6), 797-800

Pinty, B., Gobron, N., Widlowski, J.-L., Gerstl, S.A.W., Verstraete, M.M., Antunes, M., et al., 2004. RAMI II: The second radiative transfer model intercomparison exercise. Journal of Geophysical Research 109 (D6), D06210.

Potter, E., Wood, J., Nicholl, C., 1996. Sunscan Canopy Analysis System, User Manual v1. 05. Delta-T Devices Ltd., Cambridge, UK. , In: http://www.delta-t.co.uk/ manual.html.

Remmel, T.K., Csillag, F., Mitchell, S., Wulder, M., 2005. Integration of forest inventory and satellite imagery: a Canadian status assessment and research issues. Forest Ecology and Management 207, 405-428.

Salovaara, K.J., Thessler, S., Malik, R.N., Tuomisto, H., 2005. Classification of Amazonian primary rain forest vegetation using Landsat ETM+ satellite imagery. Remote Sensing of Environment 97, 39-51.

Silbernagel, J., Moeur, M., 2001. Modeling canopy openness and understory gap patterns based on image analysis and mapped tree data. Forest Ecology and Management 149, 217-233.

Strahler, A.H., 1996. Vegetation canopy reflectance modelling: Recent developments and remote sensing perspectives. Remote Sensing Reviews 15, 179-194.

Thenkabail, P.S., Enclona, E.A., Ashton, M.S., Legg, C., De Dieu, M.J., 2004. Hyperion, IKONOS, ALI, and ETM+ sensors in the study of African rainforests. Remote Sensing of Environment 90, 23-43.

Vogelmann, J.E., Howard, S.M., Yang, L., Larson, C.R., Wylie, B.K., Van Driel, N., 2001. Completion of the 1990s National Land Cover Data set for the conterminous United States from Landsat thematic mapper data and ancillary data sources. Photogrammetric Engineering and Remote Sensing 67, 650-662.

Wang, L., Sousa, W.P., Gong, P., Biging, G.S., 2004. Comparison of IKONOS and Quickbird images for mapping mangrove species on the Caribbean coast of Panama. Remote Sensing of Environment 91, 432-440.

Wickham, J.D., Stehman, S.V., Smith, J.H., Yang, L., 2004. Thematic accuracy of the 1992 National Land-Cover Data for the western United-States. Remote Sensing of Environment 91, 452-468.

Wilkinson, G.G., 2005. Results and implications of a study of fifteen years of satellite image classification experiments. IEEE Transactions on Geoscience and remote sensing 43 (3), 433-440.

Wulder, M.A., Deshka, J.A. Gillis, M.A, Luther, J.E, Hall, RJ., Beaudouin, A, Franklin, S.E., 2003. Operational mapping of the land cover of the forested area of Canada with Landsat data: EOSD land cover program. Forest Chronicles 79, 1075-1083.

$\mathrm{Xu}$, B., Gong, P., Seto, E., Spear, R., 2003. Comparison of gray-level reduction and different texture spectrum encoding methods for land-use classification using a panchromatic IKONOS image. Photogrammetric Engineering and Remote Sensing 69 (5), 529-536. 